Atmos. Chem. Phys., 13, 10573-10590, 2013

www.atmos-chem-phys.net/13/10573/2013/

doi:10.5194/acp-13-10573-2013

(c) Author(s) 2013. CC Attribution 3.0 License.

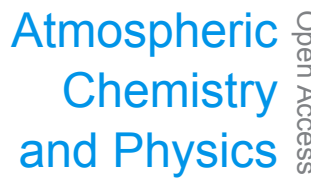

\title{
High levels of ultraviolet radiation observed by ground-based instruments below the 2011 Arctic ozone hole
}

\author{
G. Bernhard ${ }^{1}$, A. Dahlback ${ }^{2}$, V. Fioletov ${ }^{3}$, A. Heikkilä ${ }^{4}$, B. Johnsen ${ }^{5}$, T. Koskela ${ }^{4}$, K. Lakkala ${ }^{6}$, and T. Svendby \\ ${ }^{1}$ Biospherical Instruments Inc., San Diego, California, USA \\ ${ }^{2}$ Department of Physics, University of Oslo, Norway \\ ${ }^{3}$ Environment Canada, Toronto, Ontario, Canada \\ ${ }^{4}$ Finnish Meteorological Institute, Helsinki, Finland \\ ${ }^{5}$ Norwegian Radiation Protection Authority, Østerås, Norway \\ ${ }^{6}$ Finnish Meteorological Institute, Arctic Research Centre, Sodankylä, Finland \\ ${ }^{7}$ Norwegian Institute for Air Research, Kjeller, Norway
}

Correspondence to: G. Bernhard (bernhard@biospherical.com)

Received: 23 May 2013 - Published in Atmos. Chem. Phys. Discuss.: 28 June 2013

Revised: 29 August 2013 - Accepted: 9 September 2013 - Published: 1 November 2013

\begin{abstract}
Greatly increased levels of ultraviolet (UV) radiation were observed at thirteen Arctic and sub-Arctic ground stations in the spring of 2011, when the ozone abundance in the Arctic stratosphere dropped to the lowest amounts on record. Measurements of the noontime UV Index (UVI) during the low-ozone episode exceeded the climatological mean by up to $77 \%$ at locations in the western Arctic (Alaska, Canada, Greenland) and by up to $161 \%$ in Scandinavia. The UVI measured at the end of March at the Scandinavian sites was comparable to that typically observed 15-60 days later in the year when solar elevations are much higher. The cumulative UV dose measured during the period of the ozone anomaly exceeded the climatological mean by more than two standard deviations at 11 sites. Enhancements beyond three standard deviations were observed at seven sites and increases beyond four standard deviations at two sites. At the western sites, the episode occurred in March, when the Sun was still low in the sky, limiting absolute UVI anomalies to less than 0.5 UVI units. At the Scandinavian sites, absolute UVI anomalies ranged between 1.0 and 2.2 UVI units. For example, at Finse, Norway, the noontime UVI on 30 March was 4.7 , while the climatological UVI is 2.5 . Although a UVI of 4.7 is still considered moderate, UV levels of this amount can lead to sunburn and photokeratitis during outdoor activity when radiation is reflected upward by snow towards the face of a person or animal. At the western sites, UV anomalies can be well explained with ozone anomalies of up to $41 \%$
\end{abstract}

below the climatological mean. At the Scandinavian sites, low ozone can only explain a UVI increase of 50-60\%. The remaining enhancement was mainly caused by the absence of clouds during the low-ozone period.

\section{Introduction}

Ozone amounts in the Arctic stratosphere during the spring of 2011 were the lowest since satellite records began in 1979. The minimum of the daily average column ozone poleward of $63^{\circ}$ equivalent latitude was 297 Dobson units (DU) in March 2011 (Bernhard et al., 2012). This value is 18 DU below the previous record low observed in March 2000, and 100 DU (25\%) below the average for 1979-1988. While the monthly mean total ozone column observed in the Arctic was also abnormally low in March 1997 (Fioletov et al., 1997; Newman et al., 1997; Weber et al., 2012), the total ozone loss was much greater in 2011 than in 1997 (Manney et al., 2011). At some locations and times, total ozone amounts observed between February and April 2011 were more than $50 \%$ below the climatological mean (Balis et al., 2011). The fraction of the Arctic vortex with total ozone below 275 DU is typically near zero for March, but reached nearly $45 \%$ in March 2011 (Manney et al., 2011). The minimum total ozone in spring 2011 was continuously below 250 DU for about 27 days, and values between 220 and 230 DU were reached for 
about one week in late March 2011. The winter-spring ozone mass deficit in 2011 reached an extreme value of $2700 \mathrm{Mt}$ (Balis et al., 2011).

The record ozone loss in 2011 was the result of an unusually prolonged cold period in the lower stratosphere and an anomalously strong Arctic vortex, which may have partly been caused by positive sea surface temperature anomalies in the North Pacific (Hurwitz et al., 2011). The low temperatures and the strong polar vortex weakened transport of ozone from middle latitudes (Isaksen et al., 2012) and facilitated the formation of polar stratospheric clouds (PSC), which provide surfaces for heterogeneous reactions that activate stratospheric chlorine. Temperatures below the threshold temperature for PSC formation of about $-77^{\circ} \mathrm{C}$ existed between December 2010 and early April 2011. The PSC volume in 2011 was the largest on record and, in early January, the detected PSCs reached altitudes above $30 \mathrm{~km}$ where they had not been previously observed in the Arctic stratosphere (Arnone et al., 2012). Under these conditions, over $80 \%$ of the ozone present in January from about 18 to $20 \mathrm{~km}$ altitude had been chemically destroyed by late March, which is roughly twice that in the previous record-setting winters of 1996 and 2005 (Manney et al., 2011). Based on observations of the Aura Microwave Limb Sounder (MLS), Strahan et al. (2013) calculate that the PSC-driven ozone loss averaged over the vortex was 84 DU with a 12 DU $(1 \sigma)$ uncertainty. Both chemistry and transport anomalies for 2011 stand out as extreme, greater than two-sigma events, while the total anomaly is nearly three-sigma (Isaksen et al., 2012).

The amount of ozone loss and the chemistry of the Arctic stratosphere in the spring of 2011 was remarkably similar to that commonly observed in Antarctica, justifying the conclusion that there was an Arctic ozone hole in 2011 (Garcia, 2011).

Short episodes (one day to one week) of abnormally low ozone columns are frequently observed throughout the midlatitudes of both hemispheres and have been labeled "ozone mini-holes" (Newman et al., 1988). These phenomena are typically caused by a superposition of horizontal advection and vertical air motion, usually occurring when ozone-poor subtropical air masses are advected polewards and eastwards (Krzyścin, 2002). In extreme cases, mini-holes can increase erythemal UV irradiance by $75 \%$ (Antón et al., 2007). The large UVI anomalies observed in the spring of 2011 are attributable to the ozone-depleted Arctic vortex and are therefore the result of a different mechanism than UV increases caused by these ozone mini-holes.

Based on the anticorrelation between total ozone and surface UV radiation (e.g., ACIA, 2005), it can be expected that ultraviolet (UV) radiation in the Arctic was abnormally large in the spring of 2011. It is the objective of this paper to quantify these anomalies using measurements of thirteen groundbased instruments (scanning spectroradiometers and multifilter instruments) located throughout the Arctic and Scandinavia. The analysis is based on the UV Index (UVI), which is a measure of the ability of UV radiation to cause erythema (sunburn) in human skin (WHO, 2002). The UVI is a dimensionless number and calculated by weighting the spectral UV irradiance from Sun and sky that is received on a horizontal surface with the action spectrum for erythema (McKinlay and Diffey, 1987), integrating the weighted spectrum over the wavelength range $290-400 \mathrm{~nm}$, and multiplying the result by $40 \mathrm{~m}^{2} \mathrm{~W}^{-1}$. Because filter radiometers have a better time resolution than spectroradiometers (e.g., 1 measurement per minute versus 1-4 scans per hour), the study also addresses the effect of sampling rates on derived UVI anomalies.

In addition to the ozone column, UV radiation at the ground depends on many factors such as the solar zenith angle (SZA), surface albedo, and the amount and type of clouds (ACIA, 2005). These factors also affect the change in UVI for a given change in ozone (Micheletti et al., 2003). The UV response during noon hours may therefore be different from that earlier or later in the day. Our analysis recognizes this dependency by assessing several data products, namely anomalies in the noontime UVI averaged over $\pm 1 \mathrm{~h}$ about solar noon, the daily maximum UVI, the daily erythemal dose, and the cumulative erythemal dose observed during the lowozone period of 2011. As will be shown, results for any of these data products confirmed the exceptional nature of the UV observations in 2011.

Ground-based measurements are more accurate under cloudy conditions than estimates of the surface UVI from satellite observations (e.g., Krotkov et al., 1998, 2001), in particular at high latitudes where the surface is frequently covered by snow. Satellite-based estimates can be too low by up to $50 \%$, when high albedo from snow and ice cover which can increase the UVI by up to $55 \%$ (Bernhard et al., 2007) - is misinterpreted as clouds (Tanskanen et al., 2007).

Because the Sun is low in the sky at high latitudes, Arctic UVIs are considerably smaller compared to lower latitudes, which may lead to the notion that UV radiation in the Arctic is not important. This impression is not accurate for two reasons: (i) the day length in the Arctic can be as long as $24 \mathrm{~h}$. UV doses received over $24 \mathrm{~h}$ periods, which are relevant for organisms that cannot escape the Sun, are comparable to those observed at lower latitudes (Bernhard et al., 2010); (ii) UV reflections from snow-covered surfaces can lead to considerable UV exposure to a person's face (Cockell et al., 2001) or the eyes of an animal. In the years since ozone depletion was first observed over the Arctic, UV radiation effects such as sunburn have been reported in regions where they were not previously observed (Fox, 2000). Large increases in surface UV radiation at Arctic locations caused by low-ozone amounts have been reported in the past (Kerr and McElroy, 1993; Jokela et al., 1993; Taalas et al., 1996; Gurney, 1998; Kaurola et al., 2000; Lakkala et al., 2003). Changes in Arctic UV radiation are therefore a reason for concern for human health (De Fabo, 2005) and nature (Crutzen, 1992). 


\section{Locations}

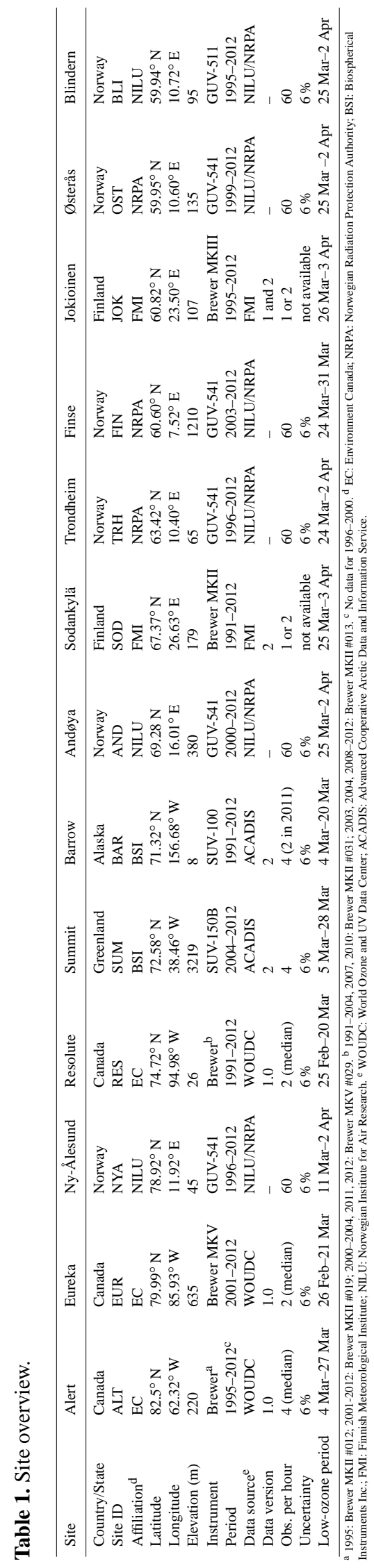

Ground-based data from thirteen Arctic and Scandinavian locations (Fig. 1) were used in this analysis. Sorted by decreasing latitude, the thirteen sites are Alert, Eureka, Ny-Ålesund, Resolute, Barrow, Summit, Andøya, Sodankylä, Trondheim, Finse, Jokioinen, Østerås, and Blindern. Essential information such as the sites' latitude, longitude, and instrumentation is provided in Table 1. Climatic conditions are briefly discussed below, with additional information available from the literature cited.

Alert is located on Ellesmere Island, Nunavut, close to the northernmost point of Canada, and about $800 \mathrm{~km}$ from the North Pole. The surface is snow-covered for 10 months of the year. Eureka is also located on Ellesmere Island, about $480 \mathrm{~km}$ southwest of Alert, and has the lowest average annual temperature and least precipitation of any weather station in Canada, with mean temperatures between $-38^{\circ} \mathrm{C}$ in February and $+5{ }^{\circ} \mathrm{C}$ in July (http://climate.weather.gc.ca/climate normals/index_e.html). Resolute is located on Cornwallis Island, Nunavut, about $600 \mathrm{~km}$ south of Eureka.

Ny-Ålesund is at the west side of the Svalbard archipelago, north of Norway. Despite its high northern latitude, the climate is relatively mild with mean temperatures between $-14^{\circ} \mathrm{C}$ in February and $5{ }^{\circ} \mathrm{C}$ in July because of the influence of the Gulf Stream. Summit is located near the top of the Greenland ice cap with a surface albedo larger than 0.97 all year round (Bernhard et al., 2008a). Barrow is close to the northernmost point of Alaska, at the coast of the Chukchi Sea, which is typically covered by ice between November and July. Snow cover extends roughly from October to June. The effective surface albedo is $0.83 \pm 0.08( \pm 1 \sigma)$ during March and April and below 0.15 in the summer (Bernhard et al., 2007).

Andøya is located on the Norwegian coast north of the Arctic Circle. Winters are fairly mild and snow cover is thin. Sodankylä is located in northern Finland and surrounded by boreal pine forests and peatlands. Snow cover typically persists from November until the end of May (Lakkala et al., 2003). Trondheim is located close to the coast of central Norway and has a predominantly hemiboreal oceanic climate. The instrument at Finse is located at an alpine site in south-central Norway at $1210 \mathrm{~m}$ above sea level and about $250 \mathrm{~m}$ above the tree line. The Hardangerjøkulen glacier (size of $73 \mathrm{~km}^{2}$ ) is located $3 \mathrm{~km}$ to the south. The site is typically snow-covered between the months of September and June/July. Jokioinen is in the southwest of Finland on the southern edge of the boreal forest belt, and has a temperate climate influenced by westerly winds. Snow cover extends from December to March. The instrument at Østerås is located in a suburb about $9 \mathrm{~km}$ northwest of the center of Oslo. Blindern is the main campus of the University of Oslo, located about $6 \mathrm{~km}$ east of Østerås and $3 \mathrm{~km}$ north of Oslo. Measurements of the last two sites present the opportunity to assess variations in UV on a regional scale. 
Additional information on the Norwegian climate is provided at http://www.yr.no/klima/.

\section{Instruments and measurement protocols}

Measurements at the three Canadian sites (Alert, Eureka, Resolute) are performed with single-monochromator Brewer spectrophotometers (Kerr et al., 1985), which measure global spectral irradiance between 290 and $325 \mathrm{~nm}$ with a bandpass of approximately $0.55 \mathrm{~nm}$ full width at half maximum (FWHM). Because the erythemal action spectrum (McKinlay and Diffey, 1987) is defined for wavelengths up to $400 \mathrm{~nm}$, an adjustment is required to correct for the instruments' limited wavelength range: the UVI is based on actual measurements up to $325 \mathrm{~nm}$ plus an additional contribution to account for radiation in the $325-400 \mathrm{~nm}$ interval, which is estimated from actual measurements at $324 \mathrm{~nm}$. The extrapolation method has been tested on many occasions and the associated error is typically less than $2 \%$ (Fioletov et al., 2004). The instruments have temperature stabilization and are calibrated once every 1-2 yr with DHX $1000 \mathrm{~W}$ tungsten halogen lamps, which are traceable to the US National Institute of Standards and Technology (NIST). The wavelength calibration is tested several times per day with a mercury discharge lamp. The wavelength uncertainty is $\pm 0.05 \mathrm{~nm}$ $( \pm 2 \sigma)$. Measurements of single-monochromator Brewer instruments are affected by stray light. Bais et al. (1996) have shown that systematic errors in Brewer UVI data due to stray light are smaller than $1 \%$ for SZAs between $20^{\circ}$ and $65^{\circ}$. Using model calculations, we confirmed that stray light errors are also below $1 \%$ for SZAs between $65^{\circ}$ and $90^{\circ}$ and ozone columns between 230 and 550 DU. Measurements are corrected for spikes (i.e., an anomalous high or low measurement at a single wavelength of a measured spectrum), the dark current, dead time of the instruments' photomultiplier tube, stray light (Fioletov et al., 2000), changes in responsivity between calibrations as well as angular response (or cosine) errors (Fioletov et al., 2002). The overall random uncertainty for Canadian Brewer field measurements has been estimated at $6 \%(2 \sigma)$ (Fioletov et al., 2001). During several periods, two instruments were operating at Alert and Resolute (Table 1). When this was the case, data of both instruments were used.

The six Norwegian sites (Ny-Ålesund, Andøya, Trondheim, Finse, Østerås, and Blindern) are part of the Norwegian UV monitoring network operated by the Norwegian Radiation Protection Authority (NRPA) and the Norwegian Institute for Air Research (NILU) (Aalerud and Johnsen, 2006). At all sites but Blindern, measurements are performed with GUV-541 multi-filter radiometers from Biospherical Instruments Inc. (BSI), which measure spectral irradiance at 305, $313,320,340$, and $380 \mathrm{~nm}$ with a bandwidth of approximately $10 \mathrm{~nm}$. At Blindern, a GUV-511 is installed, which does not have a channel at $313 \mathrm{~nm}$. The instruments return a

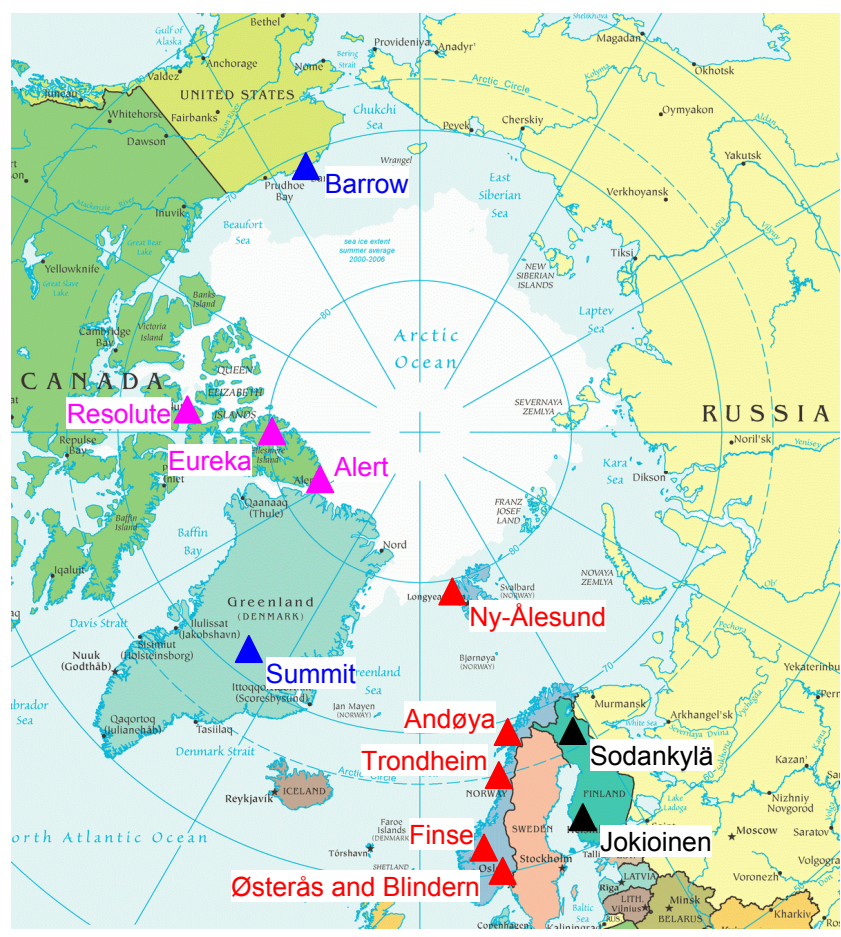

Fig. 1. Locations of instruments operated by Environment Canada (pink), Biospherical Instruments Inc. (blue), the Norwegian Radiation Protection Authority and the Norwegian Institute of Air Research (red), and the Finnish Meteorological Institute (black).

data set every minute, which is the average of samples taken at a frequency of approximately $1 \mathrm{~Hz}$ during the preceding minute. The UVI is calculated via a linear combination of measurements at the five channels. Corrections are applied for the instruments' cosine error and for systematic errors that depend on SZA (Johnsen et al., 2008, 2009). Instruments are inspected daily.

The absolute calibration of the network instruments is traceable to the QASUME (Quality Assurance of Spectral Ultraviolet Measurements in Europe; Gröbner et al., 2006) European travelling reference spectroradiometer. Calibrations were established during the FARIN (Factors Controlling UV Radiation In Norway) international solar intercomparison campaign, which took place in Oslo in 2005 (Johnsen et al., 2008). All network instruments were co-located during this campaign with the reference spectroradiometer and also characterized in the laboratory, resulting in a homogenization of their irradiance scales. The maintenance of a stable irradiance scale for the 1995-2011 period is based on annual site visits with the network's travelling reference GUV instrument (TRI). The assessment of drift of the TRI itself is based on relative measurements on a set of stable $1000 \mathrm{~W}$ lamps in the laboratory, and by vicarious solar intercomparisons of the TRI against a DM150BC double-grating spectroradiometer from Bentham instruments, which is also part of the monitoring network. 
The expanded uncertainty (coverage factor $k=2$ ) of the GUV's UVI measurements is $6 \%$ (Aalerud and Johnsen, 2006). This value takes into account the uncertainty of measurements of the Bentham spectroradiometer, the Benthamto-GUV transfer uncertainty, and drifts of the GUV sensitivities between calibrations. Blind test intercomparisons between the TRI and the QASUME spectroradiometer visiting Ny-Ålesund in 2009 and Oslo in 2010 showed average agreement in UVI measurements to within $\pm 1 \%$ for the two campaigns (Gröbner et al., 2010 and http://www.pmodwrc.ch/ euvc/euvc.php?topic=qasume_audit). Results of these campaigns confirmed the accuracy specifications.

Instruments at Barrow and Summit are operated by BSI and were part of the National Science Foundation (NSF) Spectral Irradiance Monitoring Network until 2009 (Booth et al., 1994). Both instruments are now affiliated with NSF's Arctic Observing Network (http://www.arcus. org/search/aon) and the Network for the Detection of Atmospheric Composition Change (NDACC, http://www.ndsc. ncep.noaa.gov/). The instrument at Summit is an SUV-150B spectroradiometer from BSI. It was installed in 2004 and measures spectral global irradiance between 280 and $600 \mathrm{~nm}$, with a resolution of $0.63 \mathrm{~nm}$ FWHM at a rate of four spectra per hour (Bernhard et al., 2008a). The instrument's irradiance collector consists of a polytetrafluoroethylene (PTFE) diffuser covering the entrance port of an integrating sphere, resulting in a cosine error of less than $2 \%$ for incidence angles smaller than $75^{\circ}$. The instrument took part in the fifth North American Interagency Intercomparison for UV Spectroradiometers in 2003 (Wuttke et al., 2006; Lantz et al., 2008). The instrument at Barrow is an SUV-100 spectroradiometer from BSI and was installed in 1991 (Bernhard et al., 2007). The system provides similar measurements to those of the instrument at Summit, but has a larger resolution of $1.0 \mathrm{~nm}$. Its sampling rate is typically four spectra per hour (one spectrum per hour before 1997, two spectra per hour in 2011). The reduced sampling rate in 2011 has little consequence because the area surrounding Barrow was snow-covered during the time of the low-ozone event. The high snow albedo reduces UV variability introduced by variations in cloud cover (Bernhard et al., 2007) and, in turn, the effect of the low sampling rate. Instruments are inspected every 1 to 2 days and calibrated every two weeks using $200 \mathrm{~W}$ lamps that are traceable to the source-based spectral irradiance scale realized by NIST in 1990 (Walker et al., 1987; Yoon et al., 2002). Additional information on calibration and quality control is published annually in Network Operations Reports (e.g., Bernhard et al., 2008b). Data from Summit and Barrow used in this study are part of the "Version 2" NSF network data edition (Bernhard et al., 2004), which have been corrected for drifts in responsivity, wavelength alignment errors (by means of Fraunhofer line correlation), and cosine errors. The expanded uncertainty (coverage factor $k=2$ ) of UVI data varies between 5.8 and $6.2 \%$, depending on sky conditions (Bernhard et al., 2007, 2008a).
Measurements at the two Finnish sites (Sodankylä and Jokioinen) are overseen by the Finnish Meteorological Institute (FMI). The instrument at Sodankylä is a single monochromator Brewer (model MKII) measuring the solar spectrum between 290 and $325 \mathrm{~nm}$, while the Jokioinen site uses a double-monochromator Brewer (model MKIII) covering the wavelength range of $286.5-365 \mathrm{~nm}$ (Lakkala et al., 2008). Both instruments have a spectral bandwidth of $0.6 \mathrm{~nm}$ FWHM, are inspected daily, and are calibrated monthly with DXW $1000 \mathrm{~W}$ irradiance standards, which are traceable to the scale of irradiance provided by Aalto University, Finland (AALTO). Measurements are corrected for spikes (Meinander et al., 2003), the dark current and dead time of the instruments' photomultiplier tube, stray light, the temperature dependence of the responsivity, changes of responsivity between calibrations, wavelength shifts, and the cosine error of the fore optics (Lakkala et al., 2008). To calculate the UVI, measurements are extrapolated out to $400 \mathrm{~nm}$ with a "relative spectrum" method by generating the non-measured spectral irradiances as $E(\lambda)=R(\lambda) E\left(\lambda_{\text {ref }}\right)$, where $E\left(\lambda_{\text {ref }}\right)$ is the actual measured irradiance at the reference wavelength $\lambda_{\text {ref }}(324$ or $361 \mathrm{~nm}$ for Brewer MKII and MKIII, respectively) and $R(\lambda)$ is the mean ratio $E(\lambda) / E\left(\lambda_{\text {ref }}\right)$ calculated from a large set of full-range UV spectra under clear sky. The combined measured and extrapolated irradiance spectrum is then weighted with the action spectrum for erythema and integrated over the entire wavelength range. The extrapolation method has been tested using solar spectra measured between 290 and $400 \mathrm{~nm}$ by two Bentham spectroradiometers, concluding that extrapolation uncertainties are smaller than $\pm 0.2 \%$ for Brewer MKIII data. For the Brewer MKII data, uncertainties are smaller than $\pm 1 \%$ for $\mathrm{SZA}<60^{\circ}$, but may reach up to $\pm 3 \%$ for larger SZAs. In absolute terms, errors remain below \pm 0.03 UVI units.

Spectra are measured at predefined airmasses, typically resulting in 3 to 4 spectra within $\pm 1 \mathrm{~h}$ of local solar noon. The instruments have participated in several intercomparison campaigns and were also regularly compared with the QASUME reference spectroradiometer (Bais et al., 2003). Results indicate that measurements from the two Brewer instruments are consistently high by 1-6\% compared to measurements of the QASUME instrument. Data have not been adjusted to the irradiance scale of the QASUME instrument. Measurements of both sites are regularly submitted to the European Database of UV radiation (EUVDB; http://uv.fmi.fi/ $\mathrm{uvdb} /$ ), where they undergo an automated quality flagging process that includes checking for wavelength scale errors, spikes, and anomalous high or low measurements. The expanded uncertainty, however, has not been quantified.

Total ozone data used in these studies were measured by total ozone mapping spectrometers (TOMS) onboard the Nimbus-7 (1991-1992), Meteor-3 (1993-1994), and Earth Probe (1996-2004) NASA satellites. Ozone data of the years 2005-2012 were measured by the ozone monitoring instrument (OMI) on NASA's Aura satellite. TOMS 
data are Version 8 and were downloaded from ftp://toms. gsfc.nasa.gov/pub/; OMI data are Version 8.5, Collection 3 and acquired from http://avdc.gsfc.nasa.gov/index.php?site= $1593048672 \& \mathrm{id}=28$. TOMS overpass data files include only one measurement per day. OMI overpass files include ozone data for every orbit. The daily average was calculated from these measurements. For all sites but Summit, Trondheim, and Finse, the climatological mean and range shown in the bottom panel of Fig. 3 was calculated from overpass data of the years 1991-2010. For Summit, Nimbus-7 and Meteor3 , overpass data are not available, and only Earth Probe and OMI data of the years 1996-2011 were used. Earth Probe overpass data for Trondheim, Finse, and Oslo were interpolated from gridded TOMS measurements and combined with OMI overpass data, resulting in a times series of 1996-2011.

\section{Data processing}

From the UVI data discussed in Sect. 3, several data products were calculated, including (1) the UVI measurement closest to local solar noon; (2) the UVI averaged over a period of $\pm 1 \mathrm{~h}$ centered at local solar noon; (3) the daily maximum UVI; (4) the daily erythemal dose; and (5) the erythemal dose integrated over the low-ozone periods discussed below. Data products (1), (2), and (3) were only calculated for days when there were at least two measurements within the two-hour period around noon and at least 10 measurements per day. This criterion reduces, for example, the risk that the calculated daily maximum is biased low if measurements during the noon hours are missing. The erythemal daily dose was calculated by integrating measurements over $24 \mathrm{~h}$ periods, centered at local solar noon. Data gaps were filled with spline interpolation and days with gaps longer than $7300 \mathrm{~s}$ (8500 for Jokioinen; $11000 \mathrm{~s}$ for Resolute) were excluded from further analysis. (By permitting data gaps longer than two hours during some periods at Jokioinen and Resolute, daily dose calculations for the two sites have a larger uncertainty than for the other sites.) For every single measurement, the associated SZA was calculated and the minimum SZA was determined from these data for each day. If this data-based minimum SZA exceeded the actual SZA at noon by more than $1^{\circ}$, daily dose data of that day were also not used. This procedure ensures that only days that have measurements close to the solar noon are used in the analysis.

The selection of the low-ozone periods used for data product (5) is based on total ozone measurements. For most sites, the period is defined as the range of days when OMI total ozone measurements in 2011 were below the 10th percentile, calculated from TOMS and OMI observations of all available years, excluding 2011. The start of the periods for Alert, Eureka, Ny-Ålesund, and Resolute is the day when UV measurements in 2011 exceeded the 90th percentile of historical measurements. The start was based on UV data because ozone was already depleted before the day when solar el- evation became large enough for OMI measurements. The low-ozone periods used in this study are indicated in Table 1. Cumulative erythemal doses (CEDs) for these periods were calculated by adding up the daily doses. Missing days were filled in by linear interpolation. If daily dose data were missing for more than two consecutive days or more than 3 days in total per year, CEDs were not determined. The calculation was repeated for all years to allow a comparison of the CEDs of 2011 with those of prior years.

\section{Effect of subsampling}

The Norwegian sites provide UVI data in one-minute intervals, while data of the other sites are available at rates ranging between 1 and 4 scans per hour (Table 1). The high temporal resolution of the Norwegian data sets presents the opportunity to study the effect of resolution on the calculation of the noontime average or daily maximum. For example, high UV levels beyond the clear-sky limit can sometimes be observed when the disk of the Sun is visible and additional radiation is scattered towards the observer by cumulous clouds (Mims and Frederick, 1994). Because of the transient nature of these events, they can more likely be observed by instruments with a high temporal resolution. The daily maximum UVI measured by the Norwegian instruments should therefore be biased high compared to measurements of the other sites. To test this hypothesis, data from the Norwegian sites were subsampled at 15,30, and 60 min intervals, indexed at the top of the hour; the noontime UVI (data product (2)) and daily maximum UVI (data product (3)) were calculated from these data and compared with similar data products calculated from the native, $1 \mathrm{~min}$ data. The analysis focuses on four data "classes," namely (a) the climatology of the daily noontime UVI, calculated by averaging data of all years but 2011; (b) the noontime UVI for 2011; (c) the climatology of the daily maximum UVI, calculated again by averaging data of all years but 2011; and (d) the daily maximum UVI for 2011. The average bias and standard deviation were calculated from these data and are provided in Table 2. Figure 2 shows the bias of subsampled data relative to the $1 \mathrm{~min}$ data for Ny-Ålesund and Blindern. Figure 2 and Table 2 support the following conclusions:

As can be expected, data that are subsampled at 15 min intervals have the smallest bias and standard deviation relative to the $1 \mathrm{~min}$ data, followed by data subsampled at 30 and 60 min intervals.

Standard deviations of the daily biases tend to be lowest at $\mathrm{Ny}$-Ålesund. This is likely attributable to the fact that snow cover and stratiform clouds prevail at this site for most of the year. The snow's high albedo reduces the variability introduced by clouds (Nichol et al., 2003) and, in turn, the effect of subsampling. The smallest difference between subsampled and 1 min data is observed between February and May, when the snow cover and albedo are at a maximum. 

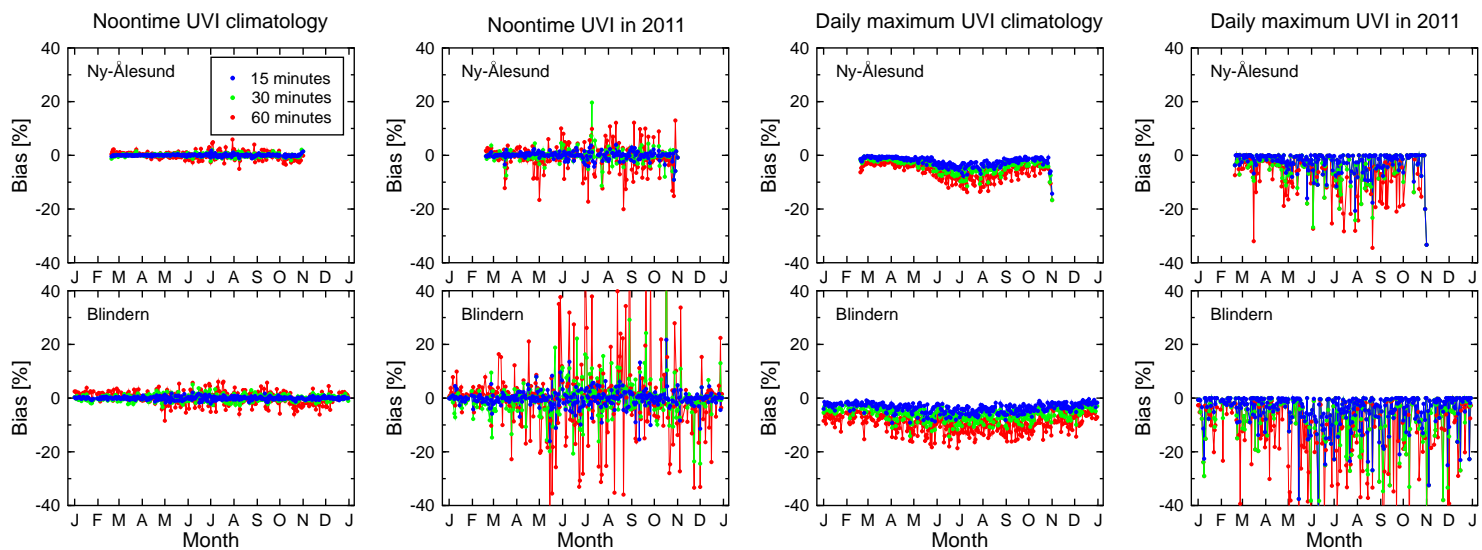

Fig. 2. Bias of subsampled data relative to the native 1-minute data for Ny-Ålesund (top) and Blindern (bottom). Data subsampled in 15, 30 and $60 \mathrm{~min}$ intervals are shown in blue, green, and red, respectively. Panels from the left to right show the bias for the noontime UVI climatology, the noontime UVI in 2011, the daily maximum UVI climatology, and the daily maximum UVI in 2011.

Table 2. Effect of subsampling. Numbers indicate the average bias \pm standard deviation in percent for subsampling at 15,30 , and 60 min, calculated from all days of the year (DOY 1-365).

\begin{tabular}{lrrrrrr}
\hline Subsampling at & Ny-Ålesund & Andøya & Trondheim & Finse & Østerås & Blindern \\
\hline \multicolumn{7}{c}{ Noontime UVI climatology } \\
15 & $0.0 \pm 0.8$ & $0.0 \pm 1.9$ & $0.0 \pm 0.8$ & $-0.1 \pm 1.1$ & $0.1 \pm 1.0$ & $0.0 \pm 1.1$ \\
30 & $0.0 \pm 0.9$ & $0.0 \pm 2.5$ & $-0.1 \pm 1.4$ & $0.0 \pm 1.7$ & $0.1 \pm 1.7$ & $0.0 \pm 1.5$ \\
60 & $0.0 \pm 1.5$ & $-0.3 \pm 4.7$ & $0.7 \pm 2.8$ & $0.7 \pm 2.7$ & $0.5 \pm 3.0$ & $0.4 \pm 2.5$ \\
15 & $-0.1 \pm 1.4$ & $-0.1 \pm 3.4$ & $-0.1 \pm 3.3$ & $0.1 \pm 3.1$ & $-0.1 \pm 3.8$ & $0.0 \pm 3.3$ \\
30 & $0.0 \pm 2.7$ & $-0.4 \pm 6.6$ & $0.1 \pm 6.2$ & $1.0 \pm 6.5$ & $-0.4 \pm 6.4$ & $0.2 \pm 7.4$ \\
60 & $-0.4 \pm 4.9$ & $-0.8 \pm 12.8$ & $0.0 \pm 12.9$ & $1.2 \pm 10.2$ & $-0.2 \pm 12.3$ & $0.1 \pm 16.9$ \\
15 & $-2.4 \pm 1.8$ & $-5.6 \pm 2.7$ & $-4.2 \pm 2.0$ & $-4.5 \pm 2.9$ & $-3.8 \pm 2.0$ & $-3.8 \pm 1.9$ \\
30 & $-3.9 \pm 2.5$ & $-8.6 \pm 3.5$ & $-7.1 \pm 2.7$ & $-7.0 \pm 4.3$ & $-6.2 \pm 2.8$ & $-6.1 \pm 2.5$ \\
60 & $-5.8 \pm 3.0$ & $-12.3 \pm 4.7$ & $-11.0 \pm 3.6$ & $-10.2 \pm 5.5$ & $-9.9 \pm 3.9$ & $-9.8 \pm 3.3$ \\
15 & $-2.5 \pm 3.9$ & $-5.6 \pm 8.1$ & $-5.2 \pm 6.4$ & $-6.0 \pm 7.2$ \\
30 & $-3.7 \pm 5.2$ & $-8.4 \pm 9.7$ & $-7.5 \pm 7.9$ & $-9.1 \pm 10.0$ & $-4.2 \pm 6.2$ & $-4.7 \pm 6.6$ \\
60 & $-6.3 \pm 7.2$ & $-12.5 \pm 12.6$ & $-12.2 \pm 11.6$ & $-12.7 \pm 12.5$ & $-11.4 \pm 12.8$ & $-11.7 \pm 12.7$ \\
\hline \multicolumn{7}{c}{ Daily maximum UVI in 2011} \\
\hline
\end{tabular}

For the "noontime UVI climatology" data class, the average bias introduced by subsampling is always smaller than $1 \%$ (Table 2): the maximum bias is $0.7 \%$, observed for 60 min subsampling at Trondheim and Finse. This result suggests that the comparatively low sampling rate of scanning spectroradiometers has little effect for establishing a noontime UVI climatology at sites where these instruments are deployed.

Subsampling has a large influence on measurements of individual days. This is evident, for example, from the large standard deviations of the "noontime UVI in 2011" data class provided in Table 2, and the large scatter in Fig. 2. Despite the large variability, the average bias is small. For example, the average biases of the "noontime UVI for 2011" data class are typically smaller than $1 \%$; the maximum bias is $1.2 \%$ (subsampling at $60 \mathrm{~min}$ intervals at Finse).

Subsampling causes a large bias for daily maxima. For subsampling at $15 \mathrm{~min}$ intervals, average biases range between -2.4 and $-6.0 \%$ and increase to up to $-12.7 \%$ for subsampling at $60 \mathrm{~min}$ intervals. Comparing daily maximum measurements of two sites with different sampling protocols can therefore lead to erroneous conclusions. Of note, average biases calculated from measurements of a single year (i.e., 2011) are only slightly larger than those of the "daily maximum UVI" climatology.

Østerås and Blindern are only $6 \mathrm{~km}$ apart. Statistics for the two sites are similar but not identical, suggesting that cloud patterns at the two sites are somewhat different. This observation is further supported by the fact that UVI 

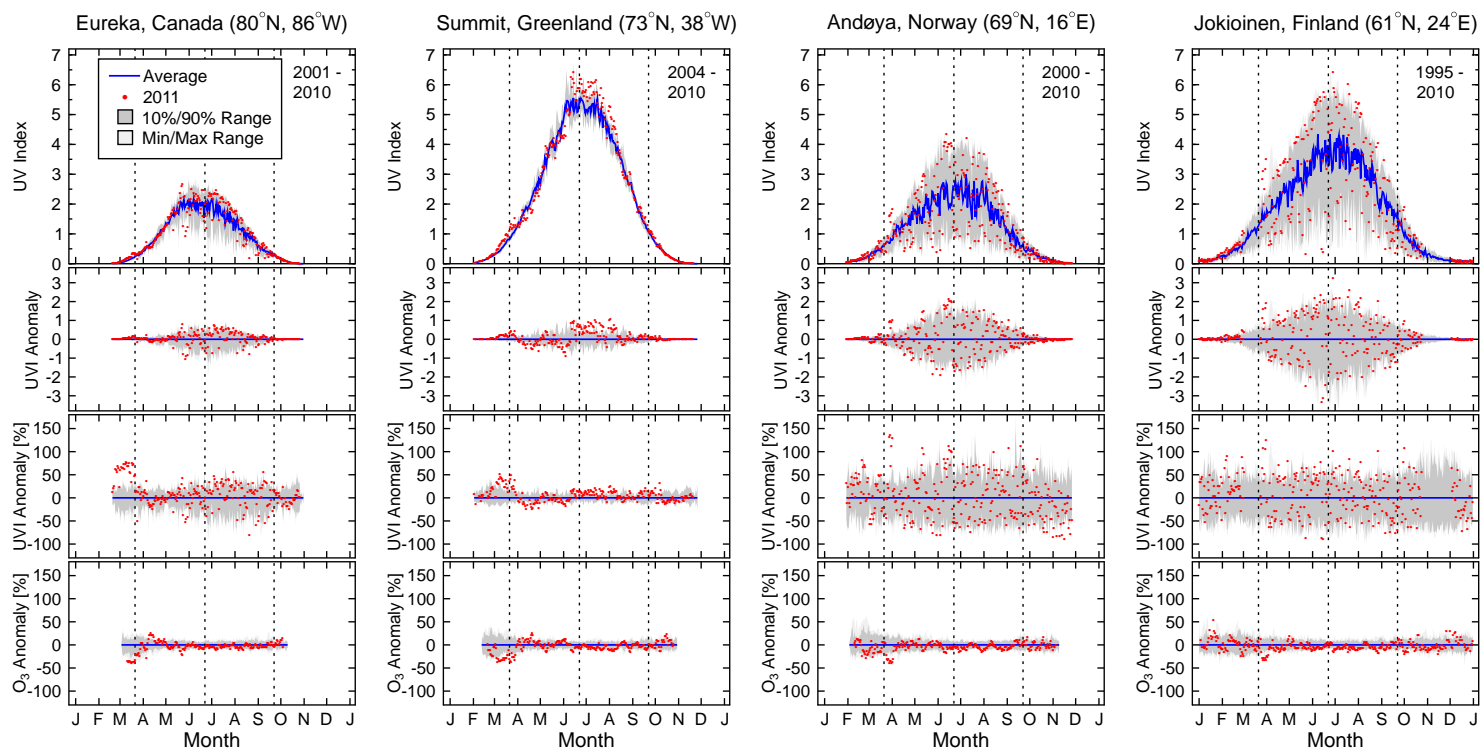

Fig. 3. Seasonal variation of the noontime UV Index at Eureka, Summit, Andøya, and Jokioinen. The top (first) panel for each site compares noontime UVI measurements performed in 2011 (red dots) with the average noontime UVI (blue line), the range between the 10th and 90th percentile (dark shading), and the range of historical minima and maxima (light shading). Average and ranges were calculated from measurements of the periods indicated in the top-right corner of the panel. The second panel shows the 2011 UVI anomaly in absolute terms, calculated as the difference between measurements and the average. The third panel shows the relative UVI anomaly calculated as the percentage departure from the climatological mean. The fourth panel shows a similar anomaly analysis for total ozone derived from satellite measurements. Data from Andøya were subsampled at 15 min intervals. Vertical broken lines indicate the times of the vernal equinox, summer solstice, and autumnal equinox, respectively.

measurements at Blindern are on average $2.5 \%$ lower than at Østerås, suggesting greater cloudiness and less and earlier disappearing snow cover at Blindern.

In summary, subsampling has little influence on the calculation of a noontime UVI climatology, but decreases the precision of calculating noontime values for individual days and causes a systematic bias when considering daily maxima.

\section{Results}

Figure 3 compares measurements of the noontime UVI (data product (2)) in 2011 with the climatological mean at Eureka, Summit, Andøya, and Jokioinen. Similar figures for other sites and data products, including results for all subsampling regimes, are available as supplements. These figures are provided as high-definition PDF files, allowing one to compare the different datasets in detail, for example, by flipping back and forth between two different graphs on a computer screen.

Figure 3 and the supplement figures are composed of four panels for each site. The top (first) panel compares noontime UVI measurements performed in 2011 (red dots) with the average (i.e., climatological mean) noontime UVI (blue line), the range between the 10th and 90th percentile (dark shading), and the range of historical minima and maxima (light shading). The climatological mean and the two ranges were calculated from measurements of the years indicated in the top-right corner of the panel. Data from Andøya were subsampled at $15 \mathrm{~min}$ intervals; data of the three other sites are based on their native time resolution. The second panel shows the 2011 UVI anomaly in absolute terms, calculated as the difference between measurements in 2011 and the climatological mean. The third panel shows the relative UVI anomaly, calculated as the percentage departure from the climatological mean. The fourth panel shows a similar anomaly analysis for total ozone derived from the TOMS and OMI measurements.

Figure 3 and the associated supplements support the following conclusions:

- Total ozone was abnormally low (i.e., below the minimum calculated from data of the years 1991-2010) during most of March at Eureka and Summit, and late March at Andøya and Jokioinen. Maximum anomalies are between $-31 \%$ (Barrow) and $-43 \%$ (Resolute). The median anomaly was $-36 \%$.

- Periods of low ozone coincide with periods of elevated UVI. This is particularly evident in data from Eureka, where the relative UVI anomaly exceeded $50 \%$ between 23 February and 19 March. The anticorrelation between ozone and the UVI is also clearly apparent in the Summit data. At the two Scandinavian sites shown in Fig. 3, the low-ozone event was between 25 March and 3 April. During this period, the UVI exceed the 


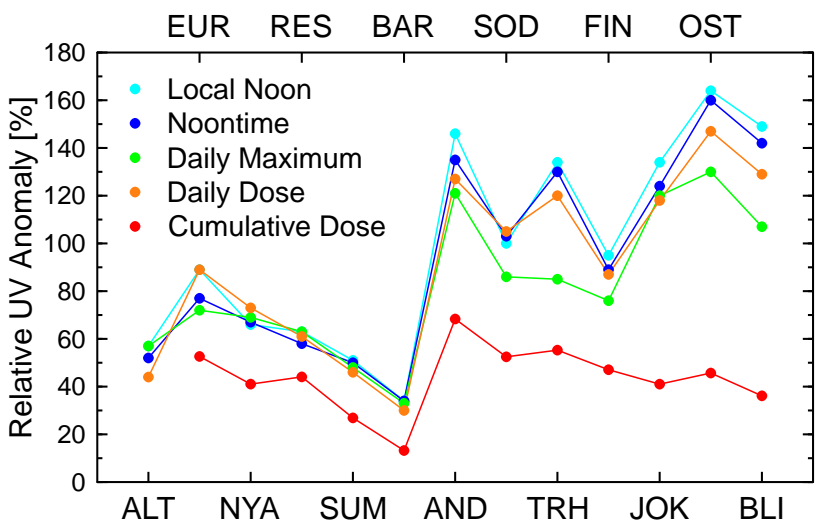

Fig. 4. Anomaly of UV measurements in 2011 relative to the climatological mean for the UVI measurement closest to local solar noon (data product (1), cyan); the UVI averaged over a period of $\pm 1 \mathrm{~h}$ centered at local solar noon (data product (2), blue); the daily maximum UVI (data product (3), green); the daily erythemal dose (data product (4), orange); and the erythemal dose integrated over the low-ozone periods (data product $(5)$, red). For data products (1)(4), data are plotted for the day when the maximum UV anomaly occurred. For the Norwegian sites, data products (2) and (3) are based on data subsampled at 15-minute intervals. Site acronyms are defined in Table 1.

climatological mean by up to $135 \%$ at Andøya and $124 \%$ at Jokioinen. Both increases were well beyond the largest UVI anomalies observed historically.

- While the magnitude of relative UVI increases was unprecedented at the four sites, the absolute increases in UV levels were either insignificant (Eureka) or modest (1.0 UVI units at Andøya and 1.9 UVI units at Jokioinen).

- The range of UVI anomalies derived from historical measurements (gray shading in Fig. 3) is much smaller for Summit than Andøya and Jokioinen. The small variability at Summit is due to the fact that the influence of clouds at this site is very limited for two reasons (Bernhard et al., 2008): first, low temperatures over the ice cap lead to low atmospheric water content and optically thin clouds. Second, the surface albedo at Summit is about $97 \%$ all year, which greatly reduces the effect of clouds (Nichol et al., 2003). The average attenuation by clouds at Summit is $3.5 \%$ in spring (1 March-21 June) and 5.8\% in summer (22 June-12 October) (Bernhard et al., 2008). Attenuation by clouds of more than $17 \%$ is observed in only $1.2 \%$ of all measurements in spring and $2.9 \%$ in summer. Enhancement by clouds is less than $10 \%$, with few $(<0.5 \%)$ exceptions. A similar analysis has not been performed for Andøya and Jokioinen. The effect of clouds during times when the surface is snowfree is instead discussed with data from Barrow, where snow cover extends roughly until June (Bernhard et al., 2007). Similar to Summit, the effect of clouds is small in spring when the surface albedo is high (e.g., the average attenuation by clouds during the first two weeks of March is $3 \pm 7 \%( \pm 1 \sigma))$. In contrast, the average attenuation during the last two weeks in August (no snow cover) is $41 \pm 22 \%$, and reductions by more than $80 \%$ are being observed. Enhancements by more than $5 \%$ beyond the clear-sky value are very rare $(<0.4 \%)$. The range of UVI anomalies (Supplement) is therefore largest in summer.

When comparing results calculated for noontime UVI with the daily maximum UVI (Supplement), several differences become apparent. Values of all statistics (climatological mean, 10th and 90th percentile, "minimum" and "maximum") are larger for the daily maximum UVI than the noontime UVI. This is trivial because for any given day, the daily maximum is by definition larger than any other data product, and so are the statistics derived from the daily values. More notably, the difference between the two data products is not the same for all statistics, but is largest for the "minimum" and smallest for the "maximum" statistic. Because of this effect, the range (gray shading in the figures) is smaller for the daily maximum data product, and the climatological mean of this data product is closer to the "maximum." This phenomenon can be explained as follows: for the noontime UVI, the "maximum" statistic is from the year with the smallest cloud attenuation at noon. While the daily maximum UVI can be higher (for example when scattered clouds enhance the UVI after noontime hours), the potential enhancement is limited to about $10 \%$, as discussed above. On the other hand, the "minimum" noontime UVI is observed when the cloud attenuation at noon was largest. It is likely that the cloud cover was less during other parts of the day, leading to a value of the daily maximum UVI that can be substantially $(>50 \%)$ above the noontime observation. At Summit, where the effect of clouds is small, there is little difference between the noontime and daily maximum statistics.

Figure 4 compares the maximum UV anomalies observed during the low-ozone period for all sites. For the western hemispheric sites, anomalies calculated for data products (1)-(4) are rather consistent and range between $30 \%$ (Barrow) and $89 \%$ (Eureka). For the Scandinavian sites, anomalies for data products (1), (2) and (4) are between $87 \%$ (Finse) and $164 \%$ (Østerås). Anomalies for data product (3) are systematically smaller for reasons explained in Sect. 7. Anomalies calculated for CEDs (data product (5)) are smaller than those of data products (1)-(4), because the period considered for this data product also includes days where the sites were close to the edge of the low-ozone region. Relative increases for CEDs range between $13 \%$ (Barrow) and $68 \%$ (Andøya). Variations of anomalies as a function of site are similar for all data products, for example, anomalies are small at Barrow and large at Andøya. 


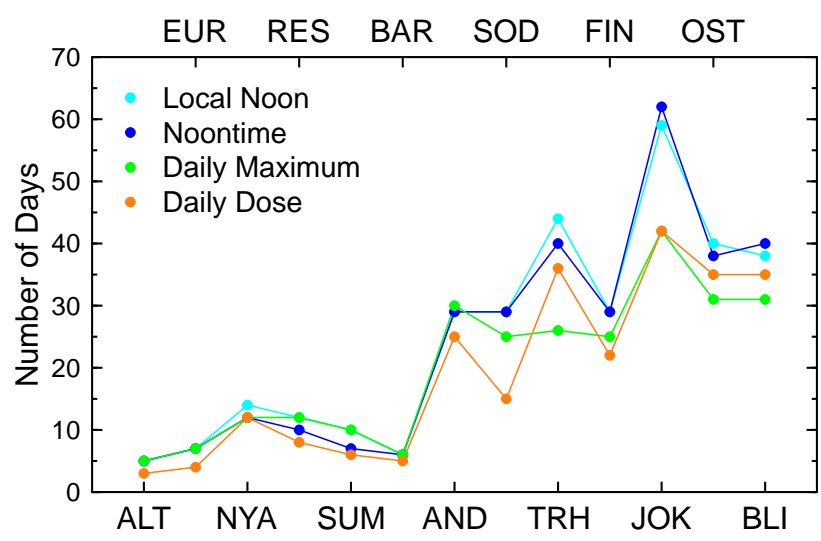

Fig. 5. Number of days between the day when the maximum relative UV increase occurred in 2011 and the day when the same UV level is typically observed. The color coding is the same as in Fig. 4.

The number of days between the day when the maximum relative increase occurred in 2011 and the day when the same UV level is typically observed is shown in Fig. 5. This metric was calculated by comparing the UV level on the day when the maximum anomaly was observed with the temporal trace of the climatological mean. At the western sites, high noontime UV levels observed in 2011 occurred between 5 (Alert) and 10 (Resolute) days earlier than normally. Results for data products (1)-(4) are rather consistent. For the eastern sites, the largest UV levels in 2011 were observed between 15 and 62 days earlier. The time difference was largest when the UVI at noon (data products (1) and (2)) was used as the criterion.

The shift is rather small at the western sites because these sites are located at high latitudes where the SZA was large at the time of the low-ozone event. Because the relative change in UVI for a $1^{\circ}$ change in SZA is much larger when the Sun is close to the horizon compared to when it is overhead, the percentage change in UVI as a function of time is much larger at the sites with the highest latitude. The effect of low ozone on $\mathrm{UV}$ is therefore surpassed within a few days as the Sun rises.

For each site, Fig. 6 compares the CED observed during the low-ozone period of 2011 with the average doses determined for the same period from all years. The CED observed in 2011 was the highest at all sites, with the exceptions of NyÅlesund and Blindern, where the doses in 1997 and 1996, respectively, were slightly larger. In those years, Arctic ozone was also abnormally low (see Svendby and Dahlback, 2002 for 1996 and Newman et al., 1997 for 1997). Low ozone columns in 1997 resulted from the conjunction of a substantial photochemical loss, favored by high levels of chlorine and cold temperatures persisting until late March, and from a large-scale dynamically-induced reduction linked to unusual meteorological conditions near the pole (Lefèvre et al., 1998).
The 2011 dose received during the low-ozone episode at Eureka exceeded the climatological mean by 5.3 standard deviations. Enhancements at the other sites ranged between 1.5 (Blindern) and 4.3 (Finse) standard deviations. Additional statistics of the high-UV episode in 2011 are provided in Appendix A.

\section{Discussion}

Anomalies quantified in Sect. 6 were based on a comparison of measurements in 2011 with climatological means. Here we compare these measured anomalies with the expected increase in UV resulting from the abnormally low total ozone column alone. Using the UVSPEC/libRadtran (Mayer and Kylling, 2005) radiative transfer model, two spectra were modeled for each site to complement observations for the day when the 2011 noontime UVI anomaly peaked. One spectrum was modeled with the ozone column of that day $\left(\Omega_{2011}\right)$ and the other with the climatological ozone amount $\left(\Omega_{\mathrm{Clim}}\right)$. Other model input parameters included the noontime SZA, surface albedo, the AFGL atmospheric constituent profile for subarctic winter (Anderson et al., 1986), the BassPaur ozone absorption cross-section (Bass and Paur, 1985), and an aerosol optical depth of 0.08 at $500 \mathrm{~nm}$. The UVI was calculated from the two spectra, resulting in $\mathrm{UVI}_{2011}$ for the ozone value of $\Omega_{2011}$ and $\mathrm{UVI}_{\mathrm{Clim}}$ for the ozone value of $\Omega_{\text {Clim }}$. A radiative amplification factor (RAF) was calculated with $\mathrm{RAF}=\ln \left(\mathrm{UVI}_{2011} / \mathrm{UVI}_{\mathrm{Clim}}\right) / \ln \left(\Omega_{\mathrm{Clim}} / \Omega_{2011}\right)$, following the formulation by Booth and Madronich (1994). The factor describes the percental change of the UVI in response to the percental change of the total ozone column. The variables $\Omega_{2011}, \Omega_{\text {Clim }}$, and RAF are shown in Table 3 along with the ozone anomaly, $\Delta \Omega$, defined as $\Delta \Omega=$ $\left(\Omega_{2011} / \Omega_{\text {Clim }}-1\right) \times 100$; the UVI anomaly computed with the model from the ozone anomaly, $\Delta \mathrm{UVI}_{\mathrm{c}}$; the observed noontime UVI anomaly relative to the climatological mean, $\triangle \mathrm{UVI}_{\mathrm{m}}$; and the observed sky condition in 2011.

Ozone anomalies $\Delta \Omega$ range between -30 and $-41 \%$, with the exception of Barrow, where $\Delta \Omega=-24 \%$. For the western sites, the computed and observed UVI anomalies agree to within $\pm 9 \%$, indicating that most of the UV increase can be explained by the decrease in ozone. For the Scandinavian sites, the observed UVI anomaly is much larger than the computed one. The largest difference is at Østerås, where $\Delta \mathrm{UVI}_{\mathrm{m}}$ is $161 \%$ and $\Delta \mathrm{UVI}_{\mathrm{c}}$ is $56 \%$. A small part of these discrepancies can be explained by the fact that changes in UVI in response to changes in ozone are smaller at large SZAs (Micheletti et al., 2003). At the western sites, the UV anomaly peaked earlier in the year when noontime SZAs were larger than $74^{\circ}$. RAFs for these sites range between 0.87 and 0.96 , indicating that a $1 \%$ change in ozone causes a change in the noontime UVI of less than $1 \%$. In contrast, SZAs are smaller than $66^{\circ}$ at the Scandinavian sites and RAFs range between 1.07 and 1.13. The larger part of 

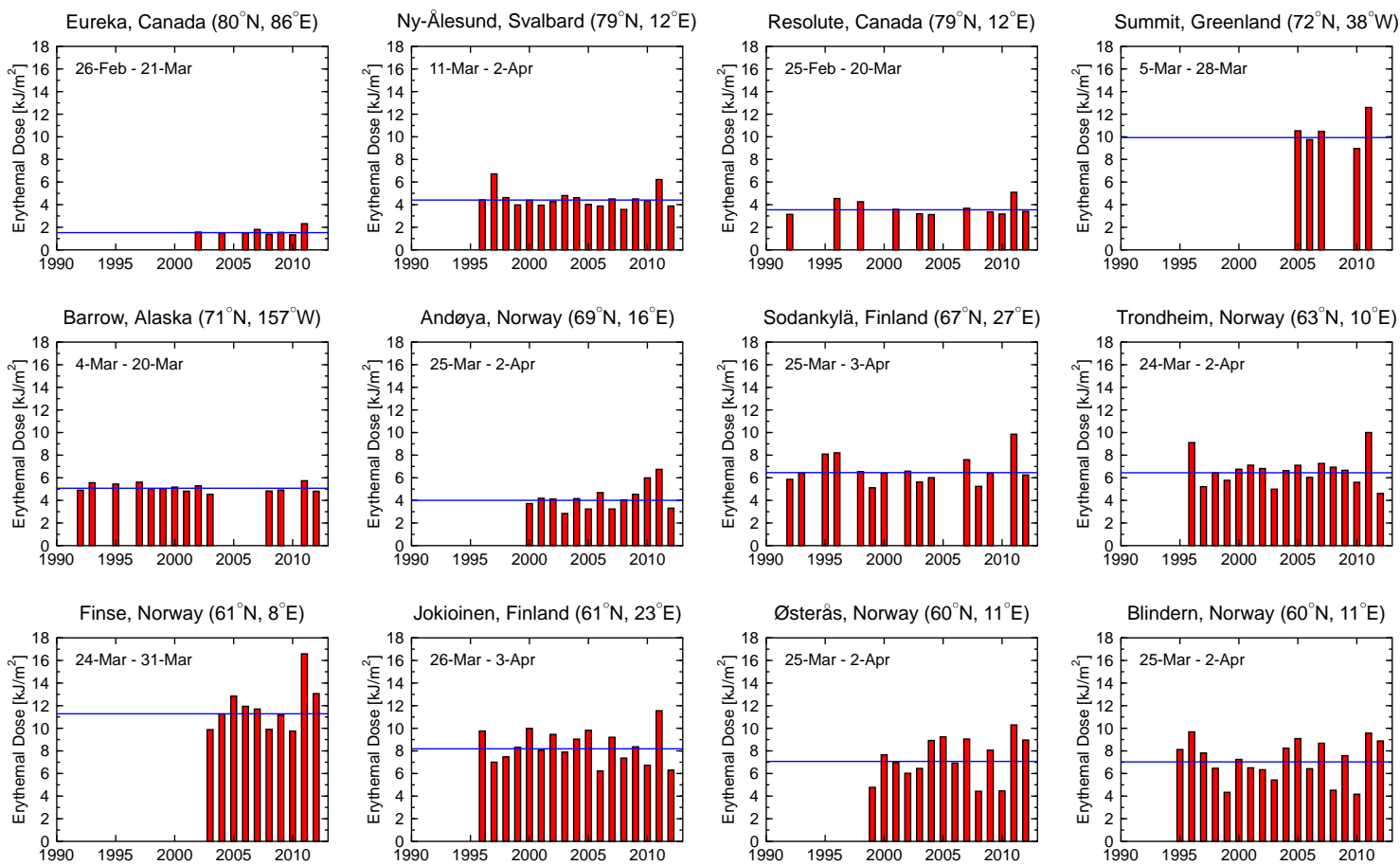

Fig. 6. Cumulative erythemal dose (CED) for the periods indicated in the top left corner of each panel. A CED of $10 \mathrm{~kJ} / \mathrm{m}^{2}$ is equivalent to 100 "standard erythemal doses" (SED) (Diffey et al., 1997). The average climatological dose for this period is indicated by a blue line. Data gaps prevented the calculation of an accurate dose at some sites and for some years. Data for Alert are not shown because of data gaps in 2011.

the difference between $\Delta \mathrm{UVI}_{\mathrm{c}}$ and $\Delta \mathrm{UVI}_{\mathrm{m}}$ can be explained by the exceptionally good weather prevailing during the period of the low-ozone episode: at all sites, the sky was either clear or covered by a thin cloud layer (Table 3). UV radiation is typically suppressed by clouds at all Scandinavian sites, which is evident from Fig. 3. The climatological mean is therefore well below clear-sky levels. To confirm that the good weather conditions can indeed explain the difference between $\Delta \mathrm{UVI}_{\mathrm{c}}$ and $\Delta \mathrm{UVI}_{\mathrm{m}}, \mathrm{UV}$ anomalies were recalculated by referencing the 2011 measurements to either the 90th percentile or the maximum of the UVI distribution, resulting in $\Delta \mathrm{UVI}_{90}$ and $\Delta \mathrm{UVI}_{\max }$. The "maximum" statistic is mostly composed of clear-sky days when total ozone was below the climatological mean and albedo was high. By using the maximum statistic as the reference for calculating the UVI anomaly, the 2011 data are compared with the largest UVI observed historically. For this reason, $\Delta \mathrm{UVI}_{\max }$ should always be smaller than $\Delta U_{V I}$. Values in Table 3 confirm that this is the case. Hence, the large UVI anomalies of 2011 can be explained by the ozone anomaly plus the fact that cloud attenuation was minimal in 2011, but has a substantial effect on the climatological mean.

The occurrence of clear skies over much of Scandinavia during the peak of the low-ozone episode at the end of March and beginning of April 2011 could be fortuitous. However, there could also be a link between the location of the strong polar vortex and local cloud conditions: a strong polar vortex could bring both low ozone and clear skies to the European North. For example, it has long been known that ozone columns anticorrelate with tropopause height (Dobson, 1929), and this observation has recently been confirmed for Arctic locations (Kivi et al., 2007). A high tropopause leads to a reduction in the total ozone column, because a larger fraction of the atmospheric column is made up of ozone-poor tropospheric air (Steinbrecht et al., 1998; Stick et al., 2006). Thus, the relatively high tropopause observed over Scandinavia on 1 and 2 April 2011 (L. Thölix, personal communication, FMI, 2013) may have contributed to the low ozone column during this period. A more detailed analysis of the correlations between tropopause height, total ozone, and weather is beyond the scope of this paper.

At Jokioinen, higher-than-normal surface albedo may have been an additional contributing factor. For example, the local albedo measured with a pyranometer during the last week of March in 2011 was 0.75 , whereas the mean for the period 1982-2013 is 0.5 . The areas surrounding Østerås were still covered by snow on 30 March 2011, while the more urban area around Blindern was snow-free. Analysis indicates that the larger albedo at Østerås increased the UVI by only $0.5-1.5 \%$. The effect of albedo at the two sites was therefore negligible. 
Table 3. Comparison of observed and computed UVI anomalies.

\begin{tabular}{|c|c|c|c|c|c|c|c|c|c|c|c|}
\hline Site $^{\mathrm{a}}$ & DOY & SZA & $\begin{array}{r}\Omega_{2011} \\
{[\mathrm{DU}]}\end{array}$ & $\begin{array}{r}\Omega_{\mathrm{Clim}} \\
{[\mathrm{DU}]}\end{array}$ & $\begin{array}{l}\Delta \Omega \\
{[\%]}\end{array}$ & $\begin{array}{r}\Delta \mathrm{UVI}_{\mathrm{c}} \\
{[\%]}\end{array}$ & $\begin{array}{r}\Delta \mathrm{UVI}_{\mathrm{m}} \\
{[\%]}\end{array}$ & RAF & $\begin{array}{r}\Delta \mathrm{UVI}_{90} \\
{[\%]}\end{array}$ & $\begin{array}{r}\Delta \mathrm{UVI}_{\max } \\
{[\%]}\end{array}$ & $\mathrm{Sky}^{\mathrm{b}}$ \\
\hline NYA & 90 & 75 & 250 & 408 & -39 & 60 & 69 & 0.96 & 42 & 33 & $\mathrm{TC}$ \\
\hline RES & 79 & 75 & 248 & 422 & -41 & 66 & 58 & 0.95 & 28 & 24 & $\mathrm{SC}$ \\
\hline SUM & 67 & 77 & 271 & 413 & -34 & 47 & 50 & 0.91 & 12 & 12 & Clear \\
\hline BAR & 71 & 75 & 335 & 442 & -24 & 27 & 34 & 0.87 & 11 & 7 & Clear \\
\hline AND & 88 & 65 & 263 & 399 & -34 & 56 & 134 & 1.07 & 67 & 54 & Clear \\
\hline SOD & 89 & 64 & 257 & 391 & -34 & 58 & 103 & 1.08 & 30 & 18 & Clear \\
\hline TRH & 89 & 60 & 261 & 373 & -30 & 49 & 131 & 1.11 & 58 & 18 & Clear \\
\hline FIN & 89 & 56 & 256 & 371 & -31 & 54 & 90 & 1.16 & 54 & 51 & $\mathrm{TC}$ \\
\hline JOK & 90 & 57 & 253 & 382 & -34 & 59 & 124 & 1.13 & 46 & 43 & Clear \\
\hline OST & 89 & 56 & 253 & 373 & -32 & 56 & 161 & 1.13 & 50 & 48 & $\mathrm{TC}$ \\
\hline BLI & 89 & 56 & 253 & 373 & -32 & 56 & 142 & 1.13 & 34 & 29 & $\mathrm{TC}$ \\
\hline
\end{tabular}

a See Table 1 for site acronyms. Data for Alert and Eureka are not shown because OMI total ozone is not available for the DOY of interest.

b $\mathrm{TC}=$ Thin clouds SC $=$ Scattered clouds; Clear = clear sky (no clouds).

Of all data products discussed in Sect. 6, anomalies relative to the climatological mean are largest for noontime measurements (Fig. 4). There is little difference depending on whether the single measurement closest to the local solar noon (data product (1)) or the average of measurements within a two-hour period centered around the noon (data product (2)) is evaluated. UV anomalies derived from the "daily maximum UVI" tend to be smaller than for noontime measurements, in particular at sites most affected by variable clouds (e.g., Scandinavian sites with low snow cover). This is mostly caused by the fact that the climatological mean for the "daily maximum UVI" data product is closer to the "maximum" statistic than is the case for the "noontime UVI" data product. Because anomalies are determined by comparing measurements with the respective climatological mean, anomalies are smaller in the case of the maximum daily UVI.

Relative anomalies calculated for daily doses (data product (4)) tend to be smaller than anomalies for the noontime UVI. This is partly due to the fact that measurements at large SZAs, when RAFs are small, also contribute to the daily dose.

The analysis of the effects of subsampling presented in Sect. 5 suggests that an accurate climatology of noontime UV measurements can be accomplished with instruments that sample at a rate of as low as one measurement per hour. This result is encouraging, considering that most spectroradiometer-based monitoring programs used low sampling rates at the beginning of the data record. However, climatologies based on daily maxima derived from these measurements are likely biased low by as much as $12 \%$, because measurements at one-hour intervals do not capture short-term spikes in UV (lasting 1 min or less) caused by broken clouds. Data for single days are much more affected than climatologies by low sampling rates with errors that may occasionally exceed $\pm 30 \%$ (Fig. 2). Anomalies calculated for the 2011 low-ozone event are fortunately only modestly affected by the sampling rate: noontime UVI anomalies calculated from the $1 \mathrm{~min}$ data agreed to within $\pm 2 \%$ with the data subsampled at $15 \mathrm{~min}$ intervals and $\pm 10 \%$ with the data subsampled at $60 \mathrm{~min}$. The effect of subsampling on the accuracy of daily dose calculations has been assessed by den Outer et al. (2005): based on UV measurements performed at $1 \mathrm{~min}$ intervals at a site in the Netherlands, den Outer et al. (2005) estimated that the upper boundary for the uncertainty in the measured daily UV dose using data at 12 min intervals is $2.2 \%$. The uncertainty in monthly and yearly doses is 0.5 and $0.2 \%$, respectively.

\section{Conclusions}

Measurements of UV radiation at thirteen Arctic and subArctic locations in the spring of 2011 were compared with long-term data records at these sites. During the low-ozone episodes in March and April 2011, measurements of the UVI and erythemal doses were amplified by up to $164 \%$ compared to the climatological mean. The magnitude of UV anomalies depends strongly on the site and to a lesser degree on the data product that is used to assess the effect.

At the western sites (e.g., Resolute, Summit, and Barrow), UV anomalies relative to the climatological mean can be well explained by the abnormally low total ozone amounts in 2011. At the Scandinavian sites, low ozone can only explain an increase in the UVI by $50-60 \%$. The remaining increase was caused by the absence of clouds during a significant portion of the low-ozone period and by later-than-normal onset of snow melt at some sites such as Jokioinen. At the highlatitude Arctic sites, the low-ozone event was already present when the Sun was a little above the horizon (e.g., solar elevation $<2^{\circ}$ at Eureka), and lasted roughly until the end of March 2011. The episode therefore occurred during a time when solar elevations were small. 
Table 4. Statistics for non-Scandinavian sites. For Ny-Ålesund, statistics are provided for the native data set and subsampled data sets at 15 and 60 min intervals, separated by a slash.

\begin{tabular}{|c|c|c|c|c|c|c|}
\hline Parameter* & Alert & Eureka & Ny-Ålesund & Resolute & Summit & Barrow \\
\hline \multicolumn{7}{|c|}{ UVI at local solar noon (data product (1)) } \\
\hline DOY max anomaly & 71 & 69 & 91 & 79 & 82 & 71 \\
\hline UVI that day & 0.12 & 0.18 & 0.79 & 0.81 & 1.37 & 0.68 \\
\hline Climatol. UVI & 0.08 & 0.09 & 0.47 & 0.50 & 0.91 & 0.51 \\
\hline UVI anomaly [\%] & 57 & 89 & 66 & 63 & 51 & 34 \\
\hline "Days too early" & 5 & 7 & 14 & 12 & 10 & 6 \\
\hline \multicolumn{7}{|c|}{ Noontime UVI (data product (2)) } \\
\hline DOY max anomaly & 71 & 68 & 90/90/90 & 79 & 67 & 71 \\
\hline UVI that day & 0.12 & 0.16 & $0.71 / 0.71 / 0.71$ & 0.77 & 0.64 & 0.67 \\
\hline Climatol. UVI & 0.08 & 0.09 & $0.42 / 0.42 / 0.42$ & 0.49 & 0.42 & 0.50 \\
\hline UVI anomaly [\%] & 52 & 77 & $69 / 67 / 72$ & 58 & 50 & 34 \\
\hline "Days too early" & 5 & 7 & $12 / 12 / 12$ & 10 & 7 & 6 \\
\hline \multicolumn{7}{|c|}{ Daily maximum UVI (data product (3)) } \\
\hline DOY max anomaly & 71 & 68 & 90/90/90 & 79 & 82 & 71 \\
\hline UVI that day & 0.12 & 0.16 & $0.76 / 0.76 / 0.74$ & 0.81 & 1.37 & 0.67 \\
\hline Climatol. UVI & 0.08 & 0.10 & $0.45 / 0.45 / 0.44$ & 0.50 & 0.92 & 0.50 \\
\hline UVI anomaly [\%] & 57 & 72 & $69 / 69 / 69$ & 63 & 48 & 34 \\
\hline "Days too early" & 5 & 7 & $12 / 12 / 12$ & 12 & 10 & 6 \\
\hline \multicolumn{7}{|c|}{ Daily erythemal dose (data product (4)) } \\
\hline DOY max anomaly & 69 & 57 & 90 & 72 & 69 & 71 \\
\hline Dose that day & 0.048 & 0.014 & 0.521 & 0.300 & 0.368 & 0.363 \\
\hline Climatol. dose & 0.033 & 0.008 & 0.301 & 0.186 & 0.252 & 0.280 \\
\hline Dose anomaly [\%] & 44 & 89 & 73 & 61 & 46 & 30 \\
\hline "Days too early" & 3 & 4 & 12 & 8 & 6 & 5 \\
\hline \multicolumn{7}{|c|}{ Cumulative erythemal dose (CED) in $\mathrm{kJ} \mathrm{m}^{-2}$; (data product (5)) } \\
\hline Low-ozone period & $\begin{array}{l}4 \text { Mar- } \\
27 \text { Mar }\end{array}$ & $\begin{array}{l}26 \mathrm{Feb}- \\
21 \mathrm{Mar}\end{array}$ & $\begin{array}{r}11 \mathrm{Mar}- \\
2 \mathrm{Apr}\end{array}$ & $\begin{array}{l}25 \mathrm{Feb}- \\
20 \mathrm{Mar}\end{array}$ & $\begin{array}{l}5 \mathrm{Mar}- \\
28 \mathrm{Mar}\end{array}$ & $\begin{array}{l}4 \text { Mar- } \\
20 \text { Mar }\end{array}$ \\
\hline CED 2011 & - & 2.32 & 6.22 & 5.1 & 12.6 & 5.74 \\
\hline Climatol. CED & - & 1.52 & 4.41 & 3.54 & 9.93 & 5.07 \\
\hline Standard dev. & - & 0.15 & 0.70 & 0.49 & 0.74 & 0.32 \\
\hline UV anomaly [\%] & - & 53 & 41 & 44 & 27 & 13 \\
\hline Anomaly in st. dev. & - & 5.3 & 2.6 & 3.2 & 3.6 & 2.1 \\
\hline Climatol. ann. dose & - & 238 & 204 & 288 & 527 & 308 \\
\hline
\end{tabular}

* See text for explanation of parameters.

The noontime solar elevation on 30 March is $12^{\circ}$ at Alert and $23^{\circ}$ at Barrow. At the Scandinavian sites, the low-ozone episode occurred between 24 March and 3 April, with solar elevations on 30 March ranging between $25^{\circ}$ (Andøya) and $34^{\circ}$ (Blindern). Because surface UV levels are first and foremost controlled by the height of the Sun above the horizon, absolute UV anomalies remained small at the high-Arctic sites despite record-low ozone amounts: the maximum absolute UVI anomaly was 0.46 UVI units and observed at Summit. At the Scandinavian sites, the absolute UVI anomaly was typically between 1.0 and 2.0 UVI units, with the maximum increase of 2.2 UVI units observed at Finse. The noontime UVI on 30 March was 4.7 at this site, while the climatological UVI is 2.5. Although a UVI of 4.7 is still considered "moderate" (WHO, 2002), UV levels of this amount can lead to sunburn and photokeratitis during outdoor activity in snow when radiation is reflected upward toward the face (Cockell et al., 2001). This is particularly a problem when high UV levels occur at a time of year when they are not expected (Abarca et al., 2002). Larger, absolute UVI increases occurred at lower latitudes in April 2011 during excursions of the polar vortex. For example, on 22 April, the clear-sky UV Index over parts of Mongolia $\left(48^{\circ} \mathrm{N}, 98^{\circ} \mathrm{E}\right)$ estimated by TEMIS (Tropospheric Emission Monitoring Internet Service at http://www.temis.nl/uvradiation/UVindex.html) was 8.6 when a lobe of the polar vortex extended to central Asia. The long-term average for this day at this location is 5.4 with a standard deviation of 0.5 , i.e., the anomaly was more than six standard deviations larger than the climatological mean.

The low-ozone event increased the CED by more than two standard deviations beyond the climatological mean at 11 sites (Appendix A). The increase was larger than three 
Table 5. Statistics for Scandinavian sites. For the Norwegian sites, statistics are provided for the native data set and subsampled data sets at 15 and 60 min intervals, separated by a slash.

\begin{tabular}{|c|c|c|c|c|c|c|c|}
\hline Parameter ${ }^{*}$ & Andøya & Sodankylä & Trondheim & Finse & Jokioinen & Østerås & Blindern \\
\hline \multicolumn{8}{|c|}{ UVI at local solar noon (data product (1)) } \\
\hline DOY max anomaly & 88 & 89 & 89 & 89 & 90 & 89 & 89 \\
\hline UVI that day & 1.68 & 2.14 & 2.66 & 4.75 & 3.62 & 3.22 & 3.15 \\
\hline Climatol. UVI & 0.68 & 1.07 & 1.14 & 2.44 & 1.55 & 1.22 & 1.27 \\
\hline UVI anomaly [\%] & 146 & 100 & 134 & 95 & 134 & 164 & 149 \\
\hline "Days too early" & 29 & 29 & 44 & 29 & 59 & 40 & 38 \\
\hline \multicolumn{8}{|c|}{ Noontime UVI (data product (2)) } \\
\hline DOY max anomaly & $88 / 88 / 88$ & 89 & $89 / 89 / 89$ & 89/89/88 & 90 & $89 / 89 / 89$ & $89 / 89 / 89$ \\
\hline UVI that day & $1.64 / 1.64 / 1.62$ & 2.10 & $2.56 / 2.56 / 2.58$ & $4.65 / 4.66 / 4.88$ & 3.50 & $3.15 / 3.14 / 3.1$ & $3.06 / 3.05 / 2.99$ \\
\hline Climatol. UVI & $0.70 / 0.70 / 0.67$ & 1.04 & $1.11 / 1.11 / 1.15$ & $2.45 / 2.47 / 2.56$ & 1.56 & $1.21 / 1.21 / 1.23$ & $1.27 / 1.26 / 1.26$ \\
\hline UVI anomaly [\%] & $134 / 135 / 141$ & 103 & $131 / 130 / 125$ & 90/89/90 & 124 & $161 / 160 / 151$ & $142 / 142 / 138$ \\
\hline "Days too early" & $29 / 29 / 29$ & 29 & $40 / 40 / 40$ & $29 / 29 / 41$ & 62 & $38 / 38 / 38$ & $40 / 40 / 35$ \\
\hline \multicolumn{8}{|c|}{ Daily maximum UVI (data product (3)) } \\
\hline DOY max anomaly & $87 / 87 / 91$ & 89 & $85 / 89 / 89$ & $88 / 89 / 88$ & 90 & $89 / 89 / 89$ & $89 / 89 / 89$ \\
\hline UVI that day & $1.88 / 1.86 / 1.87$ & 2.14 & $2.42 / 2.66 / 2.60$ & $5.29 / 4.82 / 4.89$ & 3.62 & $3.25 / 3.24 / 3.17$ & $3.15 / 3.14 / 3.05$ \\
\hline Climatol. UVI & $0.86 / 0.84 / 0.85$ & 1.15 & $1.34 / 1.44 / 1.37$ & $3.17 / 2.74 / 2.74$ & 1.65 & $1.44 / 1.41 / 1.36$ & $1.56 / 1.52 / 1.44$ \\
\hline UVI anomaly [\%] & $119 / 121 / 120$ & 86 & $81 / 85 / 90$ & $67 / 76 / 79$ & 120 & $125 / 130 / 133$ & $101 / 107 / 112$ \\
\hline "Days too early" & $26 / 30 / 26$ & 25 & $26 / 26 / 37$ & $34 / 25 / 34$ & 42 & $31 / 31 / 35$ & $31 / 31 / 33$ \\
\hline \multicolumn{8}{|c|}{ Daily erythemal dose (data product (4)) } \\
\hline DOY max anomaly & 88 & 87 & 89 & 89 & 90 & 89 & 89 \\
\hline Dose that day & 0.96 & 1.14 & 1.43 & 2.61 & 1.94 & 1.74 & 1.69 \\
\hline Climatol. dose & 0.43 & 0.56 & 0.65 & 1.39 & 0.89 & 0.70 & 0.74 \\
\hline Dose anomaly [\%] & 127 & 105 & 120 & 87 & 118 & 147 & 129 \\
\hline "Days too early" & 25 & 15 & 36 & 22 & 42 & 35 & 35 \\
\hline \multicolumn{8}{|c|}{ Cumulative erythemal dose (CED) in $\mathrm{kJ} \mathrm{m}^{-2}$ (data product (5)) } \\
\hline Low-ozone period & $\begin{array}{l}25 \text { Mar- } \\
2 \mathrm{Apr}\end{array}$ & $\begin{array}{r}25 \mathrm{Mar}- \\
3 \mathrm{Apr}\end{array}$ & $\begin{array}{r}24 \mathrm{Mar}- \\
2 \mathrm{Apr}\end{array}$ & $\begin{array}{r}24 \mathrm{Mar}- \\
31 \mathrm{Mar}\end{array}$ & $\begin{array}{r}26 \mathrm{Mar}- \\
3 \mathrm{Apr}\end{array}$ & $\begin{array}{r}25 \text { Mar- } \\
2 \mathrm{Apr}\end{array}$ & $\begin{array}{r}25 \mathrm{Mar}- \\
2 \mathrm{Apr}\end{array}$ \\
\hline CED 2011 & 6.75 & 9.85 & 10.00 & 16.59 & 11.55 & 10.30 & 9.57 \\
\hline Climatol. CED & 4.01 & 6.46 & 6.44 & 11.28 & 8.19 & 7.07 & 7.03 \\
\hline Standard dev. & 0.84 & 0.95 & 1.08 & 1.25 & 1.27 & 1.77 & 1.71 \\
\hline UV anomaly [\%] & 68 & 53 & 55 & 47 & 41 & 46 & 36 \\
\hline Anomaly in st. dev. & 3.3 & 3.6 & 3.3 & 4.3 & 2.65 & 1.82 & 1.5 \\
\hline Climatol. ann. dose & 245 & - & 321 & 499 & 372 & 366 & 360 \\
\hline
\end{tabular}

* See text for explanation of parameters.

standard deviations at seven sites (Eureka, Resolute, Summit, Andøya, Sodankylä, Trondheim, and Finse), and larger than four standard deviations at Eureka and Finse, confirming that the event was truly exceptional.

The number of days between the day when the maximum relative increase occurred in 2011 and the day when the same UV level is typically observed was between 5 to 10 days at the western sites and 15 to 62 days at the Scandinavian sites.

Severe ozone depletion like that observed in 2011 or even worse could appear for cold Arctic winters over the next decades if the observed tendency for cold Arctic winters to become colder continues into the future (Sinnhuber et al., 2011). Increases in UV radiation as large as those discussed in this paper could therefore reoccur.

\section{Appendix A}

\section{UVI anomaly statistics}

Statistics of the high-UV episode in 2011 are provided in Table 4 (non-Scandinavian sites) and Table 5 (Scandinavian sites). Statistics for sites with long data records (e.g., Barrow, Sodankylä) are generally the most robust. Results from sites with short records (Summit, Finse) or large data gaps (Resolute) should be interpreted with caution. For the Norwegian sites, statistics of data products (2) and (3) are given for the datasets derived from the native $1 \mathrm{~min}$ data and the subsampled data for 15 and 60 min sampling intervals. The following statistics were considered for data products (1)(4): the day of the year (DOY) when the maximum relative increase occurred ("DOY max anomaly"); the UV measurement on this day in 2011 ("UVI that day"); the climatological 
UV measurement for this day, calculated as the average of measurements from all available years up to 2010 ("Climatol. UVI"); the relative UVI anomaly discussed earlier ("UVI anomaly"); and the number of days between the day when the maximum UVI anomaly occurred in 2011 and the day when the same UVI is typically observed ("Days too early"). For data product (5), Tables 4 and 5 provide the following statistics: low-ozone period; the CED for the 2011 low-ozone period ("CED 2011"); the climatological dose for this period ("Climatol. CED"); the standard deviation for this period ("Standard dev."); the dose anomaly for 2011 expressed in percent ("UV anomaly"); the same anomaly expressed in multiples of standard deviations ("Anomaly in st. dev."); and the climatological annual erythemal dose ("Climatol. ann. dose"). Climatological doses are only based on years when sufficient data were available to estimate the annual dose accurately.

Tables 4 and 5 support the following conclusions:

- For the western sites, the maximum anomaly of the noontime UVI (data product (2)) occurred between DOY 76 (8 March at Summit) and DOY 79 (20 March at Resolute) and ranged between $34 \%$ (Barrow) and $77 \%$ (Eureka). For Ny-Ålesund and the Scandinavian sites, the maximum anomaly occurred between DOY 88 (29 March) and DOY 90 (31 March) and ranged between $90 \%$ (Finse) and $161 \%$ (Østerås).

- Anomalies for the daily maximum UVI (data product (3)) agree to within $\pm 5 \%$, with anomalies for data product (2) for the western sites. For the Scandinavian sites, anomalies calculated with data product (3) are below those of data product (2) by as much as $50 \%$ (Trondheim).

- Anomalies calculated for data product (1), which are based on one sample point only, and data product (2) agree to within $\pm 12 \%$ for all sites. Anomalies calculated for data products (2) and (4) agree to within $\pm 14 \%$.

- UVI anomalies calculated from the 1 min data agreed to within $\pm 2 \%$ with the data subsampled at $15 \mathrm{~min}$ intervals and $\pm 10 \%$ with the data subsampled at 60 min intervals for data product (2). For data product (3) the differences increased to $\pm 5 \%$ and $\pm 12 \%$, respectively. The larger effect of subsampling on data product (3) can be explained with transients enhancement of the UVI by clouds.

- The day of the year when the maximum anomaly occurred agrees to within \pm 1 day for data products (1)(3) for all sites but Summit. At Summit, the maximum anomaly occurred on DOY 67 for data product (2) and DOY 82 for data products (1) and (3). This apparent inconsistency is caused by the fact that UVI anomalies have local maxima at the two days of almost equal magnitude (Fig. 3), with one local maximum dominating data product (2) and the other data products (1) and (3). A similar effect also explains why the anomaly for daily dose (data product (4)) peaked at different days at Eureka, Resolute, and Summit than the anomalies for data products (1)-(3).

- Statistics for the two nearby sites Østerås and Blindern are very consistent. For example, the climatological CED and climatological annual dose agree to within 0.6 and $1.7 \%$, respectively. The good agreement is somewhat serendipitous and partly due to the different lengths of data records of the two sites: relatively low total ozone amounts in 1996 (Svendby and Dahlback, 2002) led to increased UV levels at Blindern before measurements at Østerås were available. If statistics are based only on years when data at both sites are available (1999-2012), measurements at Blindern are smaller than at Østerås by 7.0 \% (CED for 2011), $4.8 \%$ (climatological CED) and $2.0 \%$ (climatological annual dose). While these differences are still within the expanded uncertainties of the measurements, the observation could also be caused by a regional effect. For example, the terrain north of Blindern is steeper than at Østerås, which would increase the likelihood of cloud formation at Blindern when the prevailing southerly winds are lifted upwards.

\section{Supplementary material related to this article is available online at http://www.atmos-chem-phys.net/13/ 10573/2013/acp-13-10573-2013-supplement.zip.}

Acknowledgements. Funding for this study was provided by the US National Science Foundation's Office of Polar Programs Arctic Sciences Section (award ARC-1203250), the Academy of Finland through the SAARA project, and the Norwegian Climate and Pollution Agency (KLIF). We are grateful to the numerous dedicated individuals who have operated UV radiometers at the thirteen locations for many years.

Edited by: A. Hofzumahaus

\section{References}

Aalerud, T. N. and Johnsen, B. J.: The Norwegian UV Monitoring Network. Period 1995/96 to 2004, Strålevern Rapport 2006:4, Norwegian Radiation Protection Authority, Østerås, Norway, 2006.

Abarca, J. F., Casiccia, C. C., and Zamorano, F. D.: Increase in sunburns and photosensitivity disorders at the edge of the Antarctic ozone hole, southern Chile, 1986-2000, J. Am. Acad. Dermatol, 46, 193-199, 2002. 
ACIA, 2005. Arctic Climate Impact Assessment, Cambridge University Press, 1024 p., 2005.

Anderson, G. P., Clough, S. A., Kneizys, F. X., Chetwynd, J. H., and Shettle, E. O. AFGL atmospheric constituents profiles (0$120 \mathrm{~km})$, Tech. Rep. AFGL-TR-86-0110, Air Force Geophys. Lab., Hanscom Air Force Base Mass., 1986.

Antón, M., Cancillo, M. L., Serrano, A., Vaquero, J. M., and García, J. A.: Ozone mini-hole over southwestern Spain during January 2004: influence over ultraviolet radiation, Geophys. Res. Lett., 34, L10808, doi:10.1029/2007GL029689, 2007.

Arnone E., Castelli, E., Papandrea, E., Carlotti, M., and Dinelli B. M.: Extreme ozone depletion in the 2010-2011 Arctic winter stratosphere as observed by MIPAS/ENVISAT using a 2D tomographic approach, Atmos. Chem. Phys., 12, 9149-9165, doi:10.5194/acp-12-9149-2012, 2012.

Bais, A. F., Zerefos, C. S., and McElroy, C. T.: Solar UVB measurements with the double- and single-monochromator Brewer ozone spectrometers, Geophys. Res. Lett., 23, 833-836, 1996.

Bais, A. F., Blumthaler, M., Gröbner, J., Seckmeyer, G., Webb, A. R., Görts, P., Koskela, T., Rembges, D., Kazadzis, S., Schreder, J., Cotton, P., Kelly, P., Kouremeti, N., Rikkonen, K., Studemund, H., Tax, R., and Wuttke, S.: Quality assurance of spectral ultraviolet measurements in Europe through the development of a transportable unit (QASUME), in: Ultraviolet Ground- and Space-Based Measurements, Models, and Effects II, edited by: Gao, W., Herman, J. R., Shi, G., Shibasoki, K., and Slusser, J. R., SPIE, Bellingham, WA, USA, 4896, 232-238, 2003.

Balis, D., Isaksen, I. S. A., Zerefos, C., Zyrichidou, I., Eleftheratos, K., Tourpali, K., Bojkov, R., Rognerud, B., Stordal, F., Søvde, O. A., and Orsolini, Y.: Observed and modelled record ozone decline over the Arctic during winter/spring 2011, Geophys. Res. Lett., 38, L23801, doi:10.1029/2011GL049259, 2011.

Bass, A. and Paur, R. J.: The ultraviolet cross sections of ozone: 1 . The measurement, in: Atmospheric Ozone, edited by: Zerefos D. and Ghazi, A., Springer, New York, 606-616, 1985.

Bernhard, G., Booth, C. R., Ehramjian, J. C., Stone, R., and Dutton, E. G.: Ultraviolet and visible radiation at Barrow, Alaska: climatology and influencing factors on the basis of version $2 \mathrm{Na}-$ tional Science Foundation network data, J. Geophys. Res., 112, D09101, doi:10.1029/2006JD007865, 2007.

Bernhard, G., Booth, C. R., and Ehramjian, J. C.: Comparison of UV irradiance measurements at Summit, Greenland; Barrow, Alaska; and South Pole, Antarctica, Atmos. Chem. Phys., 8, 4799-4810, doi:10.5194/acp-8-4799-2008, 2008a.

Bernhard, G., Booth, C. R., Ehramjian, J. C., and Quang, V. V.: NSF Polar Programs UV Spectroradiometer Network 20062007 Operations Report, vol. 16.0, Biospherical Instruments Inc., San Diego, USA, available at http://uv.biospherical.com/report_ 0607/REPVOL16.pdf (last access: 21 June 2013), 2008b.

Bernhard, G., Booth, C. R., and Ehramjian, J. C.: Climatology of ultraviolet radiation at high latitudes derived from measurements of the National Science Foundation's Ultraviolet Spectral Irradiance Monitoring Network, in: UV Radiation in Global Climate Change: Measurements, Modeling and Effects on Ecosystems, edited by: Gao, W., Schmoldt, D. L., and Slusser, J. R., Tsinghua University Press, Beijing and Springer, New York, 544 pp., 2010.

Bernhard, G., Manney, G., Fioletov, V., Grooß, J.-U., Heikkilä, A., Johnsen, B., Koskela, T., Lakkala, K., Müller, R., Myhre, C. L., and Rex, M.: Ozone and UV radiation, in: State of the Climate in 2011, B. Am. Meteor. Soc., 93, S129-S132, 2012.

Booth, C. R. and Madronich, S.: Radiation amplification factors improved formulation accounts for large increases in ultraviolet radiation associated with Antarctic ozone depletion, in: Ultraviolet Radiation in Antarctica: Measurement and Biological Effects, Antarct. Res. Ser., 62, edited by: Weiler, C. S. and Penhale, P. A., AGU, Washington DC, USA, 39-42, 1994.

Booth, C. R., Lucas, T. B., Morrow, J. H., Weiler, C. S., and Penhale, P. A.: The United States National Science Foundation's polar network for monitoring ultraviolet radiation, in: Ultraviolet Radiation in Antarctica: Measurement and Biological Effects, Antarct. Res. Ser., 62, edited by: Weiler, C. S. and Penhale, P. A., AGU, Washington DC, USA, 17-37, 1994.

Cockell, C. S., Scherer, K., Horneck, G., Rettberg, P., Facius, R., Gugg-Helminger, A., Driscoll, C., and Lee, P.: Exposure of Arctic field scientists to ultraviolet radiation evaluated using personal dosimeters, Photochem. Photobiol., 74, 570-578, 2001.

Crutzen, P.: Ultraviolet on the increase, Nature, 356, 104-105, 1992.

De Fabo, E. C.: Arctic stratospheric ozone depletion and increased UVB radiation: potential impacts to human health, Int. J. Circumpol. Heal., 64, 509-522, 2005.

den Outer, P. N., Slaper, H., and Tax, R. B.: UV radiation in the Netherlands: assessing long-term variability and trends in relation to ozone and clouds, J. Geophys. Res., 110, D02203, doi:10.1029/2004JD004824, 2005.

Diffey, B. L., Jansén, C. T., Urbach, F., and Wulf, H. C.: Standard erythema dose - a review, Commission Internationale de l' Éclairage (CIE), Technical Report Nr. 125, CIE Central Bureau, Vienna, Austria, 5 pp., 1997.

Dobson, G. M. B., Harrison, D. N., and Lawrence, L.: Measurements of the amount of ozone in the Earths atmosphere and its reaction to other geophysical conditions, P. R. Soc. London A, 110, 660-693, 1929.

Fioletov, V. E., Kerr, J. B., Wardle, D. I., Davies, J., Hare, E. W., McElroy, C. T., and Tarasick, D. W.: Long-term ozone decline over the Canadian Arctic to early 1997 from ground-based and balloon observations, Geophys. Res. Lett., 24, 2705-2708, 1997.

Fioletov, V. E., Kerr, J. B., Wardle, D. I., and Wu, E.: Correction of stray light for the Brewer single monochromator, in: Proceedings of the Quadrennial Ozone Symposium, 3-8 July 2000, Sapporo, Japan, 369-370, 2000.

Fioletov, V. E., McArthur, L. J. B., Kerr, J. B., and Wardle, D. I.: Long-term variations of UV-B irradiance over Canada estimated from Brewer observations and derived from ozone and pyranometer measurements, J. Geophys. Res., 106, 23009-23028, 2001.

Fioletov, V. E., Kerr, J. B., Wardle, D. I., Krotkov, N. A., and Herman, J. R.: Comparison of Brewer UV irradiance measurements with TOMS satellite retrievals, Opt. Eng., 41, 3051-3061, 2002.

Fioletov, V. E., Kimlin, M. G., Krotkov, N., McArthur, L. J. B., Kerr, J. B., Wardle, D. I., Herman, J. R., Meltzer, R., Mathews, T. W., and Kaurola, J.: UV index climatology over the United States and Canada from ground-based and satellite estimates, J. Geophys. Res., 109, D22308, doi:10.1029/2004JD004820, 2004.

Fox, S. L.: Arctic climate change: observations of Inuit in the Eastern Canadian Arctic, in: Arctic Climatology Project, edited by: Fetterer, F. and Radionov, V., Environmental Working Group 
Arctic Meteorology and Climate Atlas, US National Snow and Ice Data Center, Boulder, CO, available at: http://nsidc.org/data/ g01938.html, 2000.

Garcia, R. R.: An Arctic ozone hole?, Nature, 478, 462-463, 2011.

Gröbner, J., Blumthaler, M., Kazadzis, S., Bais, A., Webb, A., Schreder, J., Seckmeyer, G., and Rembges, D.: Quality assurance of spectral solar UV measurements: results from 25 monitoring sites in Europe, 2002-2004, Metrologia, 43, S66-S71, doi:10.1088/0026-1394/43/2/S14, 2006.

Gröbner, J., Hülsen, G., Wuttke, S., Schrems, O., Simone, S. D., Gallo, V., Rafanelli, C., Petkov, B., Vitale, V., Edvardsen, K., and Stebel, K.: Quality assurance of solar UV irradiance in the Arctic, Photochem. Photobiol. Sci., 9, 384-391, doi:10.1039/b9pp00170k, 2010.

Gurney, K. R.: Evidence for increasing ultraviolet irradiance at Point Barrow, Alaska, Geophys. Res. Lett., 25, 903-906, 1998.

Hurwitz, M. M., Newman, P. A., and Garfinkel, C. I.: The Arctic vortex in March 2011: a dynamical perspective, Atmos. Chem. Phys., 11, 11447-11453, doi:10.5194/acp-11-11447-2011, 2011.

Isaksen, I. S. A., Zerefos, C., Wang, W.-C., Balis, D., Eleftheratos, K., Rognerud, B., Stordal, F., Berntsen, T. K., LaCasce, J. H., Søvde, O. A., Olivié, D., Orsolini, Y. J., Zyrichidou, I., Prather, M., and Tuinder, O. N. E.: Attribution of the Arctic ozone column deficit in March 2011, Geophys. Res. Lett., 39, 24810, doi:10.1029/2012GL053876, 2012.

Johnsen, B., Kjeldstad, B., Aalerud, T. N., Nilsen, L. T., Schreder, J., Blumthaler, M., Bernhard, G., Topaloglou, C., Meinander, O., Bagheri, A., Slusser, J. R., and Davis, J.: Intercomparison and harmonization of UV Index measurements from multiband filter radiometers, J. Geophys. Res., 113, D15206, doi:10.1029/2007JD009731, 2008.

Johnsen, B., Kjeldstad, B., Aalerud, T. N., Nilsen, L. T., Schreder, J., Blumthaler, M., Bernhard, G., Topaloglou, C., Meinander, O., Bagheri, A., Slusser, J. R., and Davis, J.: Intercomparison of global UV Index from multiband radiometers: harmonization of global UVI and spectral irradiance, WMO TD No. 1454, World Meteorological Organization, Geneva, Switzerland, 61 pp., 2009.

Jokela, K., Leszczynski, K., and Visuri, R.: Effects of Arctic ozone depletion and snow on UV exposure in Finland, Photochem. Photobiol., 58, 559-566, 1993.

Kaurola, J., Taalas, P., Koskela, T., Borkowski, J., and Josefsson, W.: Long-term variations of UV-B doses at three stations in northern Europe, J. Geophys. Res., 105, 20813-20820, 2000.

Kerr, J. B. and McElroy, C. T.: Evidence for large upward trends of ultraviolet-B radiation linked to ozone depletion, Science, 262, 1032-1034, 1993.

Kerr, J. B., McElroy, C. T, Wardle, D. I., Olafson, R. A., and Evans, W. F. J.: The automated Brewer spectrophotometer, in: Atmospheric Ozone, edited by: Zerefos, C. S. and Ghazi, A., D. Reidel Publishing, Dordrecht, the Netherlands, 396-401, 1985.

Kivi, R., Kyrö, E., Turunen, T., Harris, N. R. P., von der Gathen, P., Rex, M., Andersen S. B., and Wohltmann I.: Ozonesonde observations in the Arctic during 1989-2003: ozone variability and trends in the lower stratosphere and free troposphere, J. Geophys. Res., 112, D08306, doi:10.1029/2006JD007271, 2007.

Krotkov, N. A., Bhartia, P. K., Herman, J. R., Fioletov, V., and Kerr J.: Satellite estimation of spectral surface UV irradiance in the presence of tropospheric aerosols 1. Cloud-free case, J. Geophys. Res., 103, 8779-8793, 1998.
Krotkov, N. A., Herman, J. R., Bhartia, P. K., Fioletov, V., and Ah$\operatorname{mad}$ Z.: Satellite estimation of spectral surface UV irradiance 2. Effects of homogeneous clouds and snow, J. Geophys. Res., 106, 11743-11759, 2001.

Krzyścin, J. W.: Long-term changes in ozone mini-hole event frequency over the Northern Hemisphere derived from groundbased measurements, Int. J. Climatol., 22, 1425-1439, 2002.

Lakkala, K., Kyrö, E, and Turunen, T.: Spectral UV Measurements at Sodankylä during 1990-2001, J. Geophys. Res., 108, 4621, doi:10.1029/2002JD003300, 2003.

Lakkala, K., Arola, A., Heikkilä, A., Kaurola, J., Koskela, T., Kyrö, E., Lindfors, A., Meinander, O., Tanskanen, A., Gröbner, J., and Hülsen, G.: Quality assurance of the Brewer spectral UV measurements in Finland, Atmos. Chem. Phys., 8, 3369-3383, doi:10.5194/acp-8-3369-2008, 2008.

Lantz, K., Disterhoft, P., Slusser, J., Gao, W., Berndt, J., Bernhard, G., Bloms, S., Booth, R., Ehramjian, J., Harrison, L., Janson, G., Johnston, P., Kiedron, P., McKenzie, R., Kimlin, M., Neale, P., O’Neill, M., Quang, V. V., Seckmeyer, G., Taylor, T., Wuttke, S., and Michalsky, J.: 2003 North American interagency intercomparison of ultraviolet spectroradiometers: scanning and spectrograph instruments, J. Appl. Remote Sens., 2, 023547, doi:10.1117/1.3040299, 2008.

Lefèvre, F., Figarol, F., Carslaw, K. S., and Peter, T.: The 1997 Arctic ozone depletion quantified from three-dimensional model simulations, Geophys. Res. Lett., 25, 2425-2428, 1998.

Manney, G. L., Santee, M. L., Rex., M., Livesey, N. J., Pitts, M. C., Veefkind, P., Nash, E. R., Wohltmann, I., Lehmann, R., Froidevaux, L., Poole, L. R., Schoeberl, M. R., Haffner, D. P., Davies, J., Dorokhov, V., Gernandt, H., Johnson, B., Kivi, R., Kyrö, E., Larsen, N., Levelt, P. F., Makshtas, A., McElroy, C. T., Nakajima, H., Parrondo, M. C., Tarasick, D. W., von der Gathen, P., Walker K. A., and Zinoviev, N. S.: Unprecedented Arctic ozone loss in 2011 echoed the Antarctic ozone hole, Nature, 478, 469-475, 2011.

Mayer, B. and Kylling, A.: Technical note: The libRadtran software package for radiative transfer calculations - description and examples of use, Atmos. Chem. Phys., 5, 1855-1877, doi:10.5194/acp-5-1855-2005, 2005.

McKinlay, A. F. and Diffey, B. L.: A reference action spectrum for ultraviolet induced erythema in human skin, in: Commission International de l'Éclairage (CIE), Research Note, 6, 17-22, 1987.

Meinander O., Josefsson, W., Kaurola, J., Koskela, T., and Lakkala, K.: Spike detection and correction in Brewer spectroradiometer ultraviolet spectra, Opt. Eng., 42, 1812-1819, 2003.

Micheletti, M. I., Piacentini, R. D., and Madronich, S.: Sensitivity of biologically active UV radiation to stratospheric ozone changes: effects of action spectrum shape and wavelength range, Photochem. Photobiol., 78, 456-461, 2003.

Mims, F. M. and Frederick, J. E.: Cumulus clouds and UVB, Nature, 371, p. 291, 1994.

Newman, P. A., Gleason, J. F., McPeters, R. D., and Stolarski, R. S.: Anomalously low ozone over the Arctic, Geophys. Res. Lett., 24, 2689-2692, 1997.

Newman, P. A., Lait, L. R., and Schoeberl, M. R.: The morphology and meteorology of Southern Hemisphere spring total ozone mini-holes, Geophys. Res. Lett., 15, 923-926, 1988. 
Nichol, S. E, Pfister, G., Bodeker, G. E., McKenzie, R. L., Wood, S. W., and Bernhard, G.: Moderation of cloud reduction of UV in the Antarctic due to high surface albedo. J. Appl. Meteorol, 42, 1174-1183, 2003.

Sinnhuber, B.-M., Stiller, G., Ruhnke, R., von Clarmann, T., Kellmann, S., and Aschmann, J.: Arctic winter 2010/2011 at the brink of an ozone hole, Geophys. Res. Lett., 38, L24814, doi:10.1029/2011GL049784, 2011.

Steinbrecht, W., Claude, H., and Köhler, H.: Correlations between tropopause height and total ozone: implications for long-term changes, J. Geophys. Res., 103, 19183-19192, 1998.

Stick, C., Krüger, K., Schade, N. H., Sandmann, H., and Macke, A.: Episode of unusual high solar ultraviolet radiation over central Europe due to dynamical reduced total ozone in May 2005, Atmos. Chem. Phys., 6, 1771-1776, doi:10.5194/acp-6-1771-2006, 2006.

Strahan, S. E., Douglass, A. R., and Newman, P. A.: The contributions of chemistry and transport to low Arctic ozone in March 2011 derived from Aura MLS observations, J. Geophys. Res., 118, 1563-1576, doi:10.1002/jgrd.50181, 2013.

Svendby, T. M. and Dahlback, A.: Twenty years of revised Dobson total ozone measurements in Oslo, Norway, J. Geophys. Res., 107, 4369, doi:10.1029/2002JD002260, 2002.

Taalas, P., Kyrö, E., Jokela, K., Koskela, T., Leszczynski, K., Rummukainen, M., Damski J., and Supperi, A.: Stratospheric ozone depletion and solar UV radiation in the Arctic and its potential impact on human health in Finland, Geophysica, 32, 127-165, 1996.
Tanskanen, A., Lindfors, A., Määttä, A., Krotkov, N., Herman, J., Kaurola, J., Koskela, T., Lakkala, K., Fioletov, V., Bernhard, G., McKenzie, R., Kondo, Y., O’Neill, M., Slaper, H., den Outer, P., Bais, A. F., and Tamminen. J.: Validation of daily erythemal doses from Ozone Monitoring Instrument with groundbased UV measurement data, J. Geophys. Res., 112, D24S44, doi:10.1029/2007JD008830, 2007.

Walker, J. H., Saunders, R. D., Jackson, J. K., and McSparron, D. A.: Spectral irradiance calibrations, NBS Spec. Publ. US, Gaithersburg, MD, USA, 250-20, 1987.

Weber, M., Steinbrecht, W., Long, C., Fioletov, V. E., Frith, S. H., Stolarski, R., and Newman, P. A.: Stratospheric Ozone, in: State of the Climate in 2011, B. Am. Meteor. Soc., 93, S46-S49, 2012.

World Health Organization (WHO): Global Solar UV Index: a Practical Guide, 28 pp., published by World Health Organization (WHO), World Meteorological Organization (WMO), United Nations Environment Programme (UNEP) and the International Commission on Non-Ionizing Radiation Protection (ICNIRP), WHO, Geneva, Switzerland, available at http://www.who.int/ uv/publications/en/GlobalUVI.pdf (last access: 21 June 2013), 2002.

Wuttke, S., Seckmeyer, G., Bernhard, G., Ehramjian, J., McKenzie, R., Johnston, P., and O'Neil, M.: New spectroradiometers complying with the NDSC standards, J. Atmos. Ocean. Tech., 23, 241-251, 2006.

Yoon, H. W., Gibson, C. E., and Barnes, P. Y.: Realization of the National Institute of Standards and Technology detector-based spectral irradiance scale, Appl. Opt., 41, 5879-5890, 2002. 